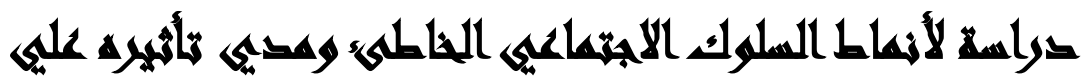

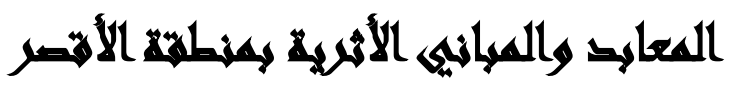

[^]

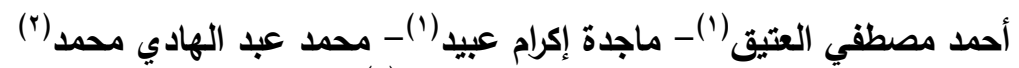

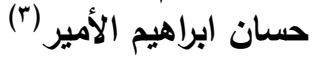

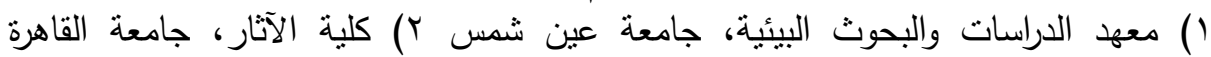
ب) المعهد العلمي الفرنسي للآثار الثرقية بالقاهرة

\section{المسرخليس}

هدفت الدراسة إلى التعرف على السلوكيات الاجتماعية الخاطئة ومدى تأثيرها على ألى الإنى

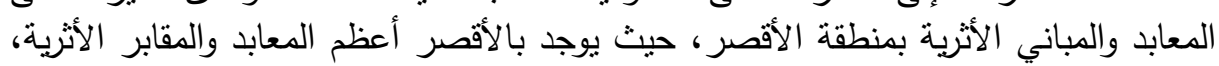

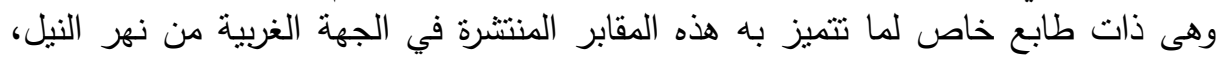

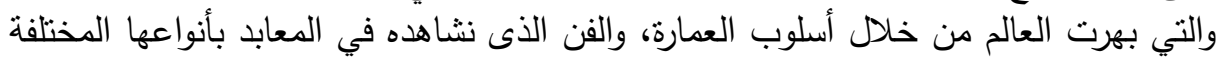

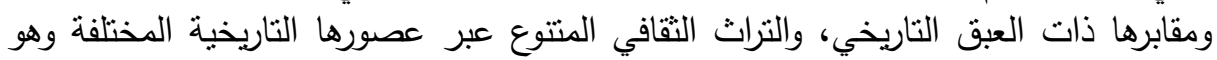

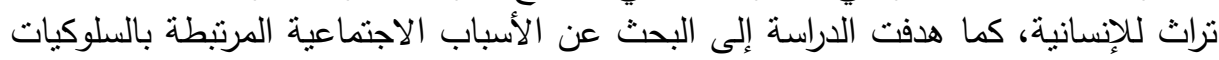

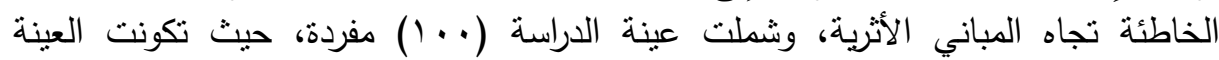

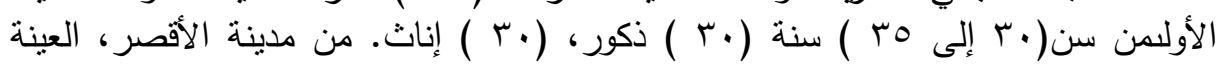

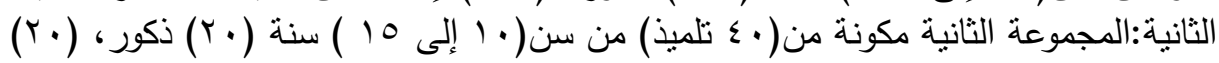

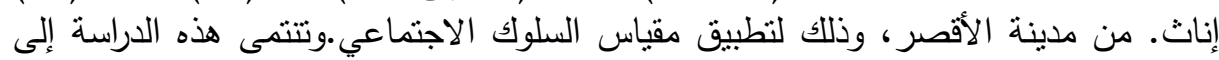

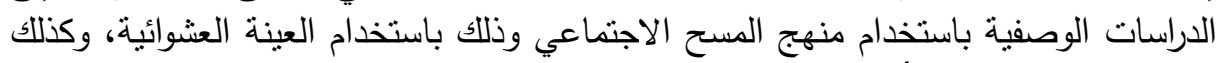

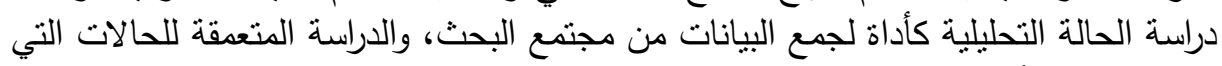

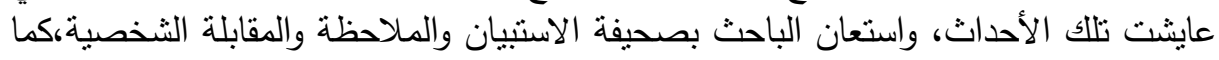

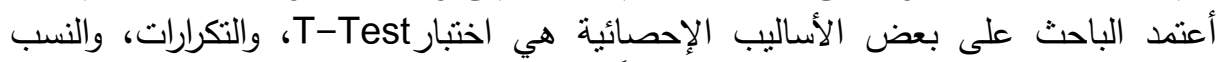

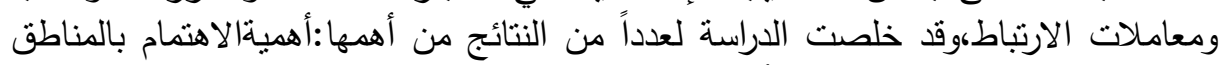

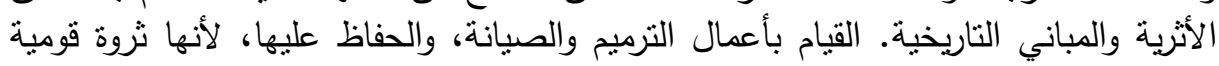

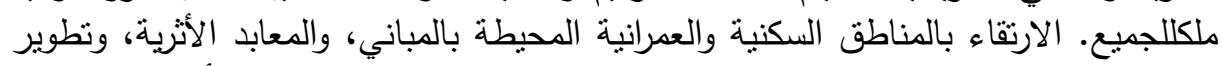

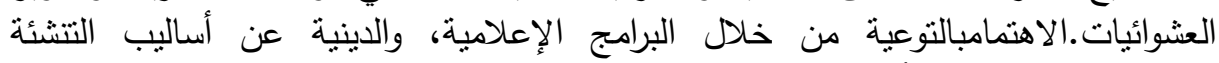

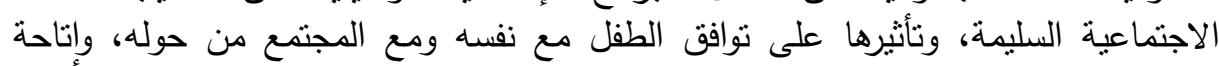
الفرصة للحوار الحر لإبقاء الاتصال بين جيل الآباء والأبناء.

$$
\text { المجلد التاسع والثلاثون، الجزء الثاني، ديسمبر r. V r }
$$




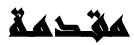

نشأت الحضارة المصرية القديمة علي ضفاف النيل،هنذ الاف السنين، وقد ورثنا عن هذه

الحضارة، نراثا حضارياً، وثقافياً، يعتبر مبعثا للفخر، ويمثل لنا ثروة فنية، وقيمة حضارية

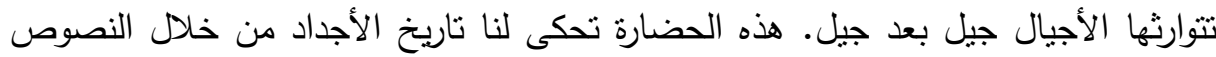

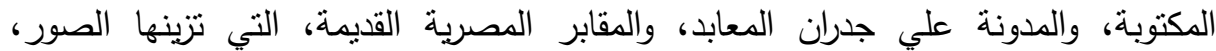

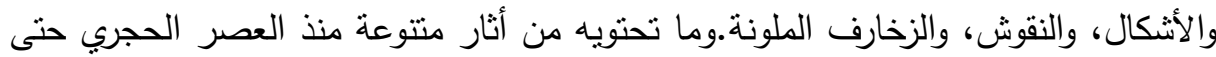
العصر الحديث المعاصر ، ومن حسن حظ مصر آن منحها الله مقومات طبيعية أدت إلى قيام حضارة مزدهرة رائدة في تاريخ حضارات العالم القديم. ولعل من أهم المقومات الطبيعية تكوين الأرض المنبسطة والصحراوات الثاسعة والتلال والهضاب التي لا تعوق حركة الاتصال بين

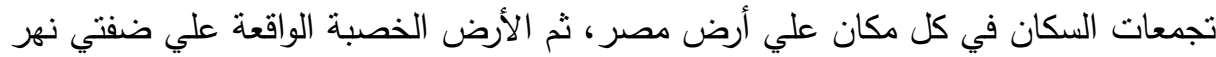
النيل.فالحضارة المصرية القديمة من الحضارات ذات مقومات عريقة بفنونها، وعمارتها، المتمثلة في الأهرامات والمعابد والمقابر المنتشرة على أرض مصر.(عبد الحليم نور

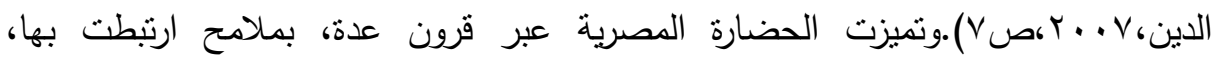

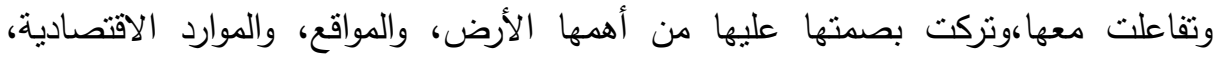

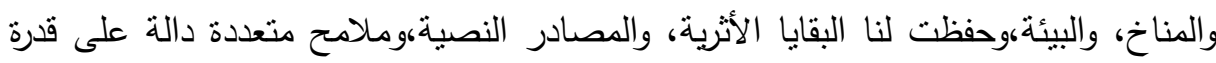
الحضارة المصرية، وأهلها في تتظيم شئون البلاد، وإدارتها في مجال الاقتصاد، الاديها

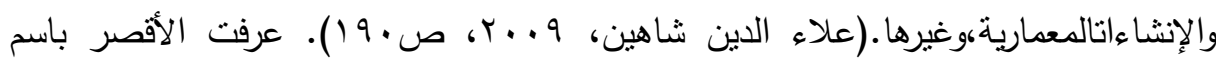
"اواسته وكانت تكتب بعلامة الصولجان، وفي عصر الدولة الوسطي ظلت أقدم مثل معروف اعلاه

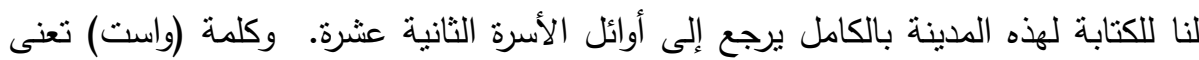

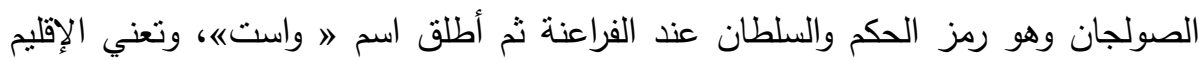

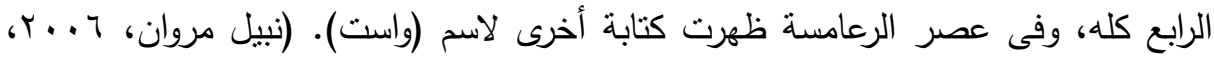

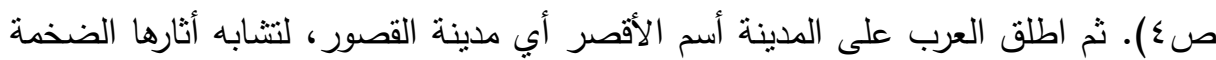

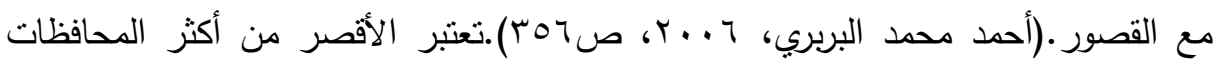

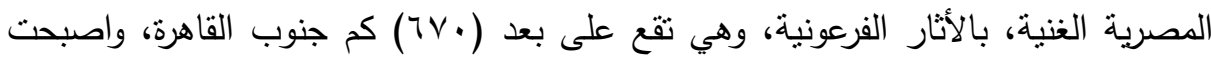

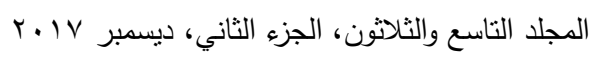




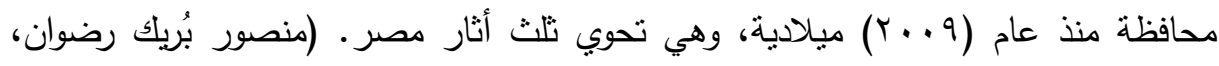

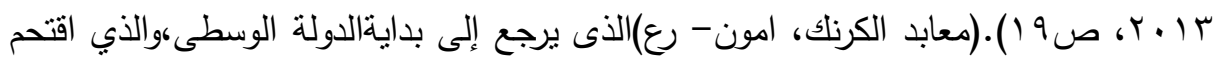

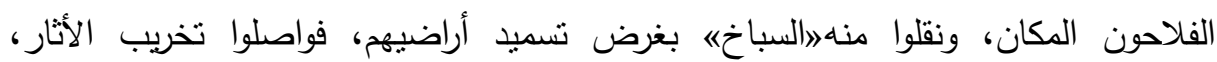

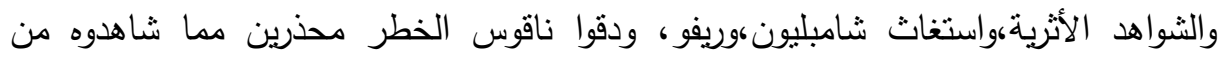
سلوك خاطئ نتيجة سلب ونهب شارك فيه العديد من الأدعياء، الذين نصبوا انفسهم منقبين

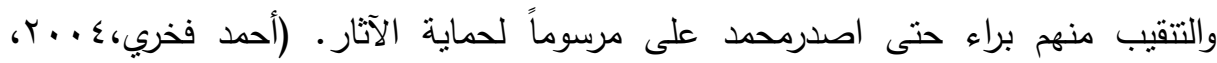

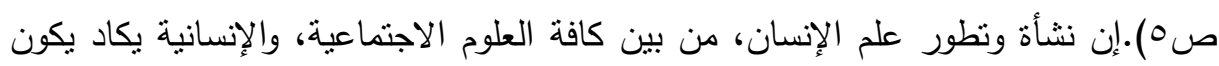

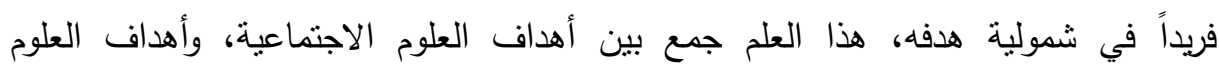

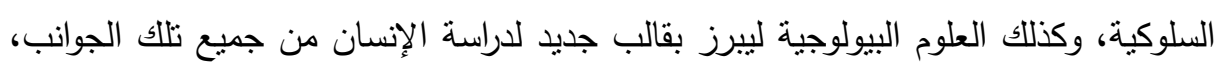

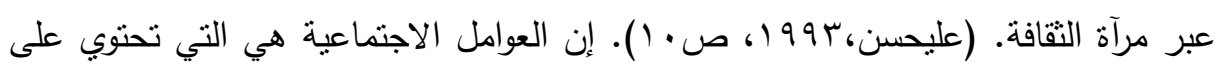

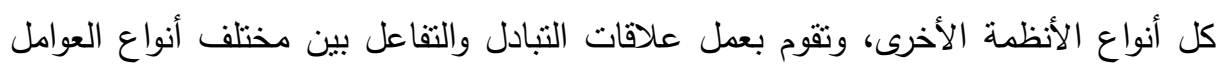
من خلال العنصر البشري المحرك لكل الأنظمة الأخرى من عادات، وتقاليد، وثقافات منوارثة.

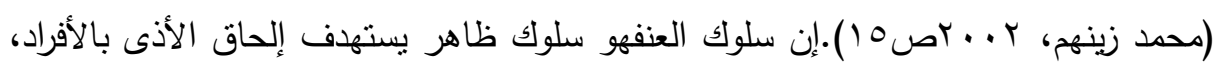
وتدمير الممتلكات العامة والخاصة، كما بعني استخدام الضغط أو القوة استخداما غير لهان

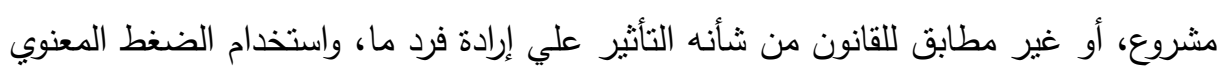

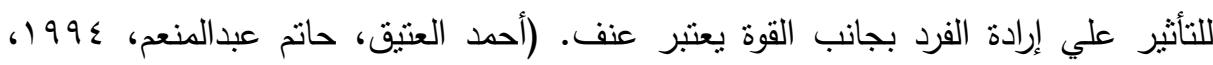

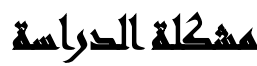

من المسلم به في السلوك الاجتماعي الخاطئ ومدى تأثيره على المعابد والمباني الأثرية.

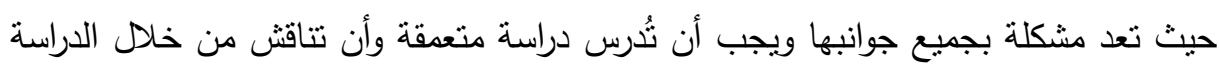

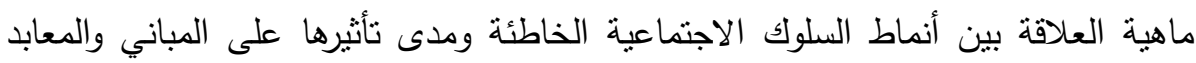

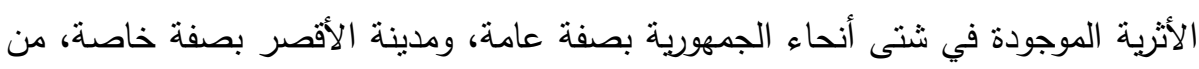
خلال التوجيه والتتظيم عند دخول الزائرين وإعدادهم أثناء زيارتهم للمعابد والمتاحف الأثرية بصفة عامة، والمقابر الأثرية لملوك وملكات مصر الفرعونية والمنتشرة بالبر الغربي من نهر

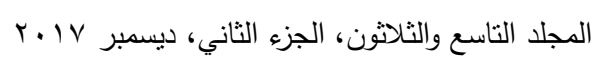


النيل وخاصةً مقابر العمال والفنيين بمنطقة دير المدينة بصفة خاصة. كما ثُلقى الدراسة الضوء على أهم المشكلات التي نعانى منها المواقع الأثرية والمعابد والمباني الأثرية نتيجة

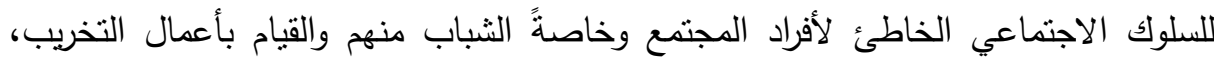
والتدمير والتلف الذى أصبح ظاهرة من مظاهر العبث، وهو ما نشاهده في وقتتا الحالي

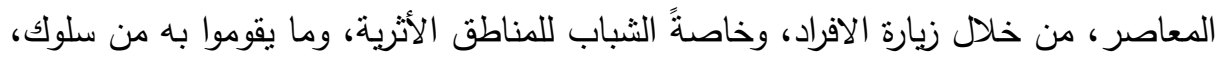

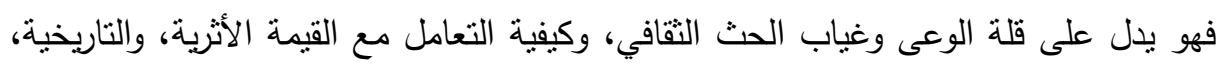
والحضارية، لهذا المكان المتواجد فيه، ولتدارك تلك الأحداث، وعدم ضياع التراث، من خلال

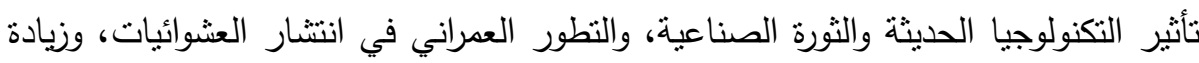
التلوث البيئي الناتج عنها، وإفساح الطريق لإقامة المشروعات وعدم التعديات على المباني

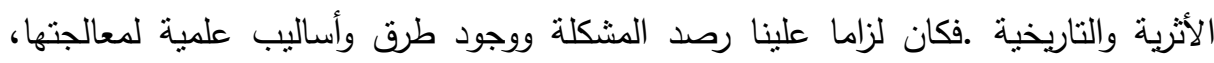

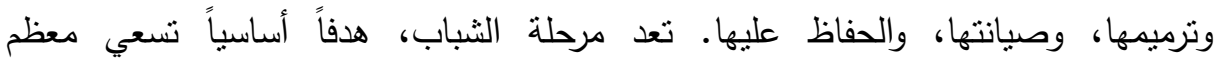

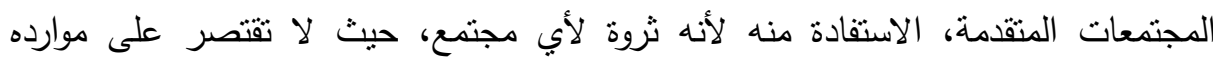

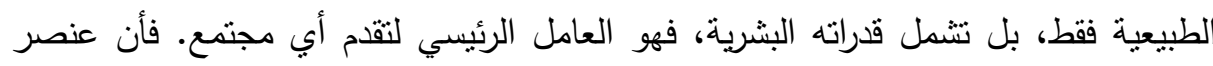
الثباب، ذو أهمية تفوق عناصر المجتمع الأخرى، حيث يعد الثباب القوة البشرية في أي لئي

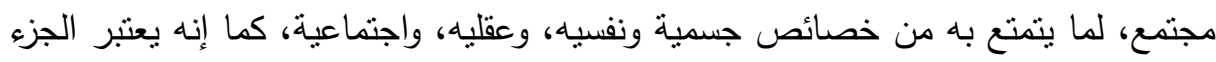

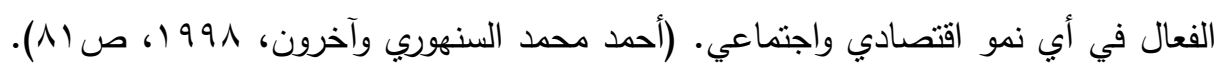
فمن الضروري دراسة السمات الاجتماعية والنفسية للشباب مكان الدراسة وذللك لما تمنتله هذه الدراسة من أهمية. كما تحدد مرحلة الثباب من خلال منظور سلوكي، باعتبارها مرحلة نشكل

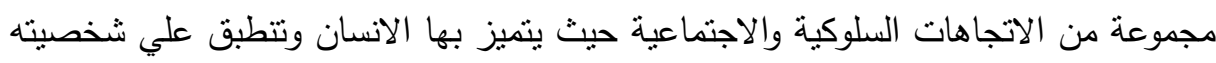

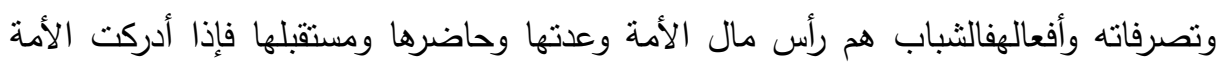

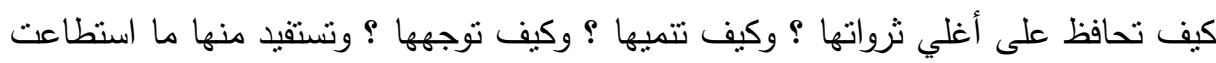

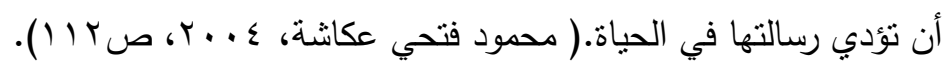




\section{تمساولايه التصراسمة}

يتحدد التساؤل الرئيسي للاراسة في معرفة: هل لأنماط السلوك الاجتماعي الخاطئ

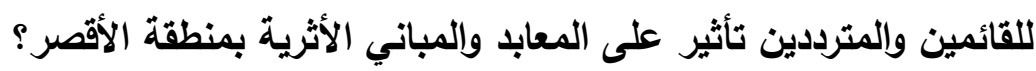
ويتفرع من هذا الهاف عدة تساؤلات فرعية وهى:

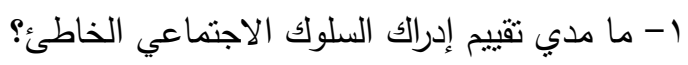

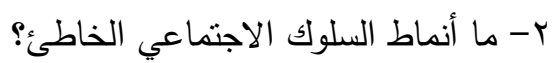

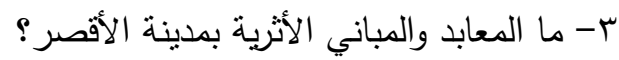

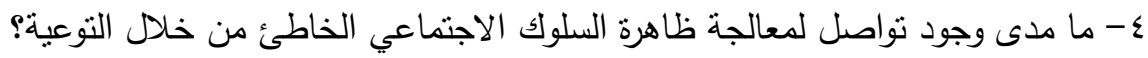

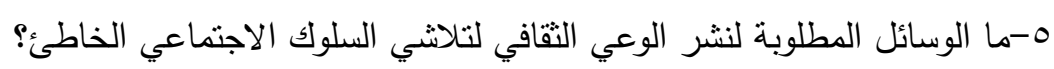

\section{أهمية التصراسلا}

- تلقى الدراسة الضوء علي الأبعاد الأساسية لأنماط السلوك الاجتماعي الخاطئ علي المعابد والمباني الأثرية.

- الاهتمام بموضوع دراسة أنماط السلوك الاجتماعي الخاطئ، حيث أنه يمتد منذ وقت بعيد.

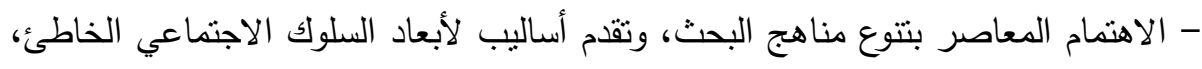
نظراً لأهمية الدراسة.

- تتصدي الدراسة الحالية، حيث أنها تسعى لدراسة أنماط السلوك الاجتماعي الخاطئ ومدى لإن تأثثرها على المعابد والمباني الأثرية.

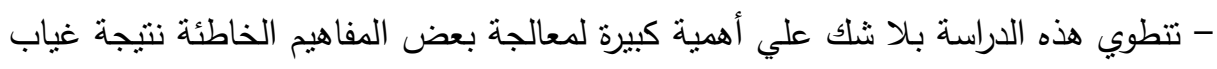

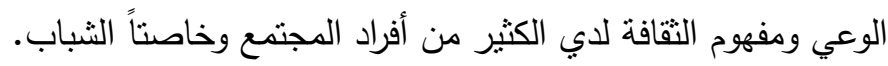

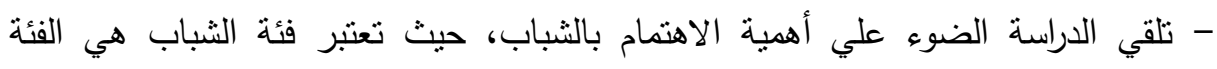

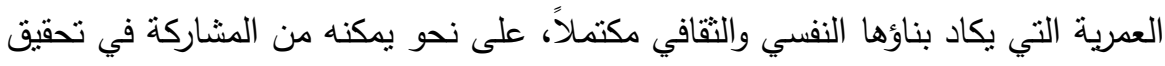

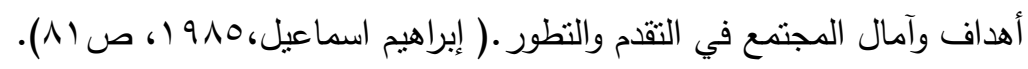


- اهتمام جميع فروع الدراسات الانسانية والعلوم الاجتماعية، بدراسة أوضاع الثباب لما يملكه الثباب من قوة، باعتبارهم أهم عناصر الإنتاج المتاحة في المجتمعات المتقدمة والنامية

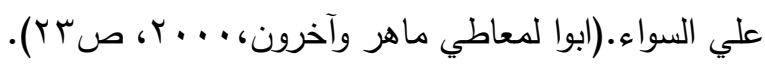

\section{الهساهيم التراسة}

يتحدد الهرف الرئيسي للاراسة في: التعرف عن الأنماط الاجتماعية للسلوكياتالخاطئة ومدى تأثثره على المعابد والمباني الأثرية بمنطقة الأقصر. ويتفرع من هذا الهذف عدة أهداف فرعية وهى: 1- التعرف علي تقيم أدراك السلوك الاجتماعي الخاطئ. r- التعرف علي أنماط السلوك الاجتماعي الخاطئ.

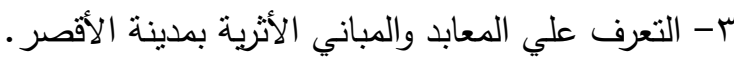
ع - التوصل إلي معالجة ظاهرة السلوك الاجتماعي الخاطئ من خلال التوعية. ه- التعرف علي وسائل نشر الوعي التقافي لتلاشي السلوك الاجتماعي الخاطئ.

\section{مخاهيه الترواسة}

ا-السمات البيئية والاجتماعية: بعرف مفهوم السمات البيئية والاجتماعية، بأنه بعض الخصائص، والمؤشرات الفعالة التي نتميز بها بيئة بعينها من الناحية الفيزيقية، والناحية الاجتماعية، والتي من المحتمل أن تؤدي دوراً في تشكيل السلوك، والتأثير فيه.

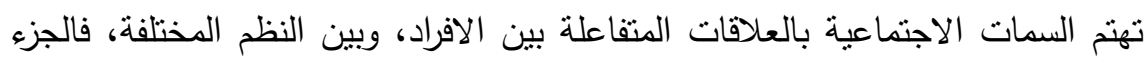

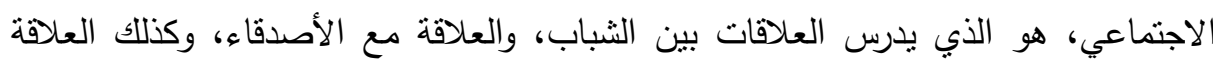

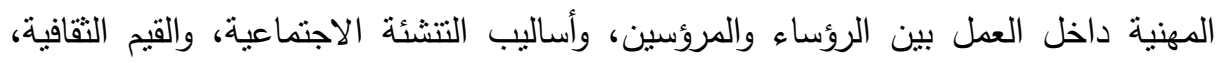
والعادات، والتقاليد، المؤثرة في الفرد والأسرة، وكذلك تدرس النواحي الاقتصادية، وألكابل، وأيضا النواحي الدينية من تعصب وتساهل، وكذلك التحيزات، والتعصبات العرقية، والطبقية، والنواحي

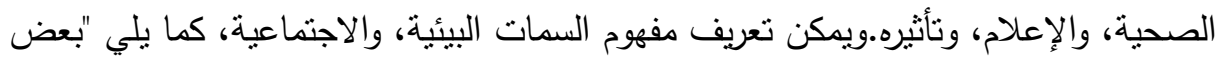

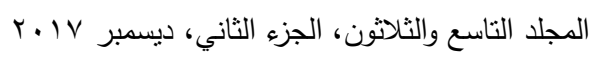


الخصائص، والمؤشرات الفعالة "النشطة"، التي تتميز بها بيئة بعينها من الناحية الفيزيقية،

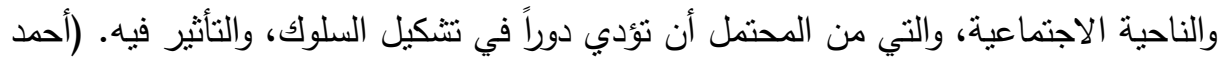

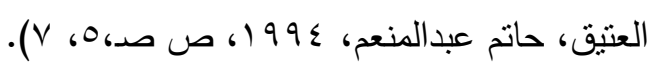

r- اعمال الشغب: ترتبط أعمال الشغب، في كثثر من جوانبها بالعشوائية، وافتقارها الي

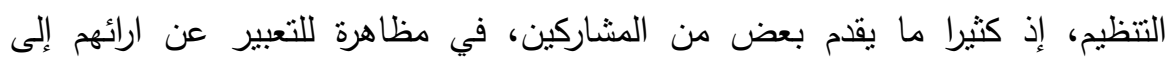

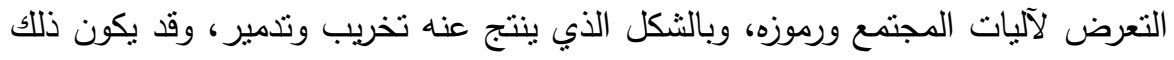
منعارضا مع الهذف، وربما يكون سببا في كثير من الأحيان إلي عمليات التخريب والتدمير ، التي تصاحب أعمال الثغب، وتتتاول الأثياء التي تهم المجتمع.(حسين نوفيق:

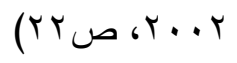

r- السلوك العدواني:يرى علماء التحليل النفسي أن هناك دافعين أساسيين يحكمان سلوك البشر ،وإنفعالاتهم، وأن بقية الدوافع الأخرى يمكن أن تتدرج تحت هذان الدافعان،وهما دافع

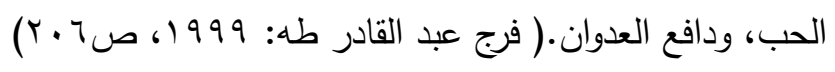

ع- الممتلكات العامة: هي الأشياء التي لا ينفرد بملكيتها شخص أو بعض الأشخاص،

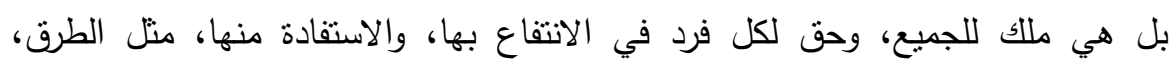

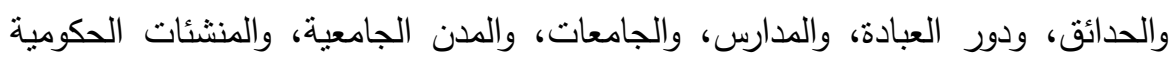

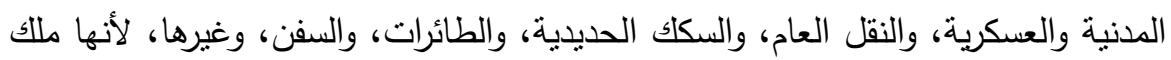

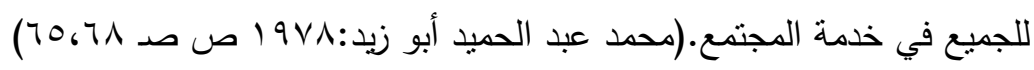

\section{السراسايت الساريها}

عبد الحكيم البلرى \& 1 ـ ب : دراسة لعوامل تلف القنون الصخرية المنفذة بمواقع المحاجر الأثرية وطرق علاجها وصيانتها تطبيقاً على جبل السلسلة ومحاجر الجرانيت بأسوان.

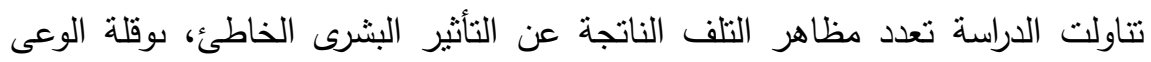
الأثري مع الأسطح الأثرية، والذى يتمنل في اللمس، والكتابات على اللوحات الصخرية، أو

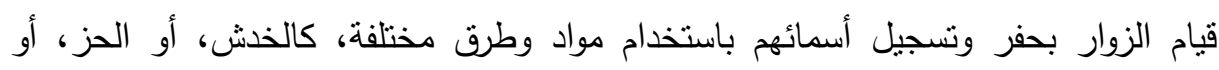

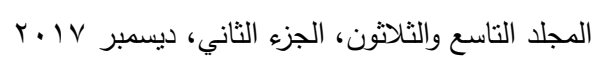


باستخدام الطباشير، ويطلق على ذلك اسم تخريب متعد Vandalism، ومن أمثلته أيضاً قيام بعض الزوار بتسلق اللوحات الصخرية، أو قطع أجزاء منها كنوع من التذكار ، أو سرقتها ومن أهم صوره أيضاً استخدام موادغير مناسبة، في عملياتعلاج وترميم أسطح الأحجار الأثرية.

مرفت ثابت صليب V . . ץ: استراتيجيات الحفاظ علي التراث الثقافي المعماري في العصور الإسلامية بمصر . هدفت الدراسة إلى الحفاظ علي المباني والمناطق التاريخية، بالترميم والصيانة، مع أهمية المشاركة الثعبية لضمان استمرارية الحفاظ عليها، ووجود مصادر للتمويل للقيام بأعمال التطوير للمناطق التزاثية، وأهية التأهيل للمباني، وجميعها تهدف إلي الحفاظ علي التراث.

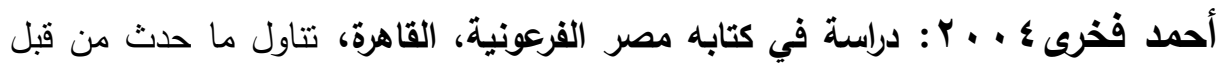

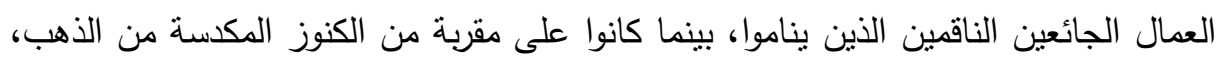

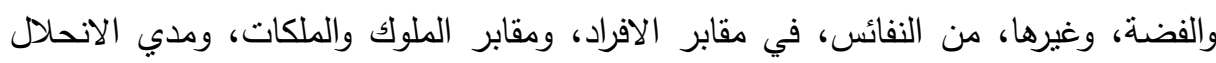

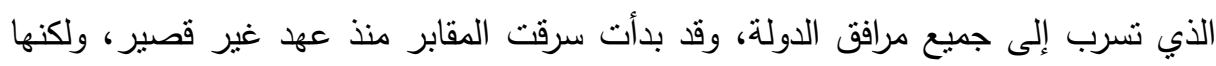

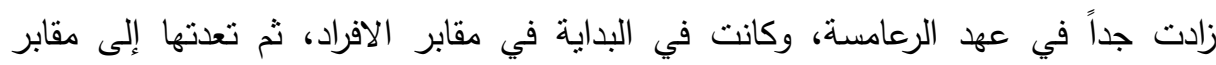

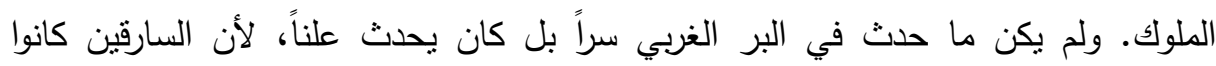

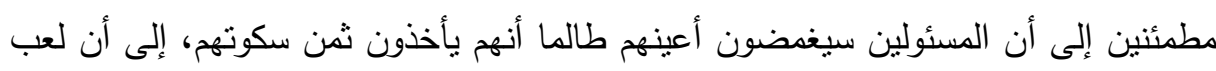
الحسد دوره بين حاكم شرقي طيبة، وبين حاكم غربي طيبة الذى كان مسئولا عنها.

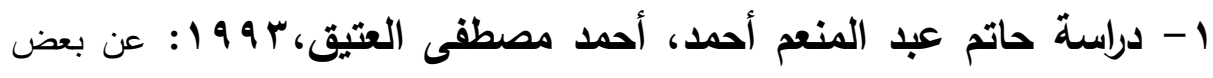
الخصائص الاجتماعية والنفسية المرتبطة بسلوك العنف نحو البيئة لدى عينة من أطفال

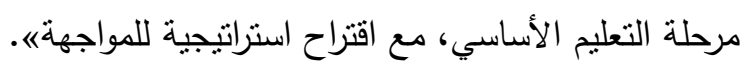

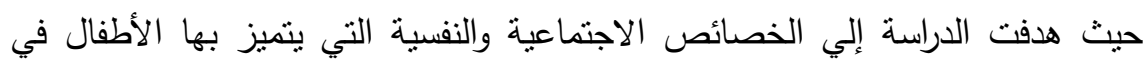
مرحلة الطفولة المتأخرة والذين يمارسون العنف نحو البيئة، مع وضع استراتيجية للمواجهة، وقد

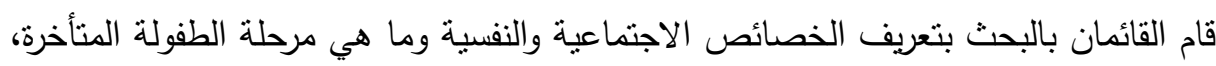
وكذلك عرف البيئة والسلوك العنيف. واستخدما المنهج العلمي وركزا على المنهج الوصفي البه 
التحليلي باستخدام المسح الاجتماعي بالعينة، والتي شملت مدارس المرحلة الابتدائية والإعدادية لتلاميذ تحت عمر با سنة وقد وقع الاختيار على مب مدرسة في نطاق القاهرة

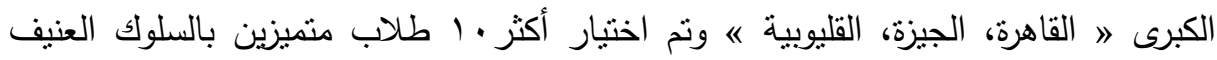

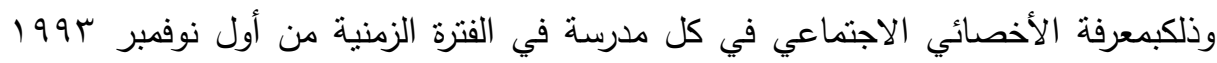

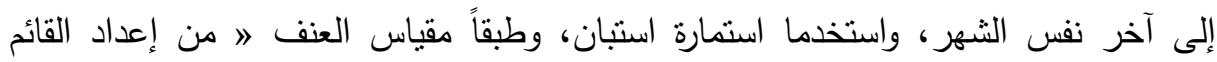
بالبحث

نتائج ما توصلا إليها من خلال البحث وهي كالآتي: - هناك ارتباط دال بين العنف والخصائص الاجتماعية عند درجة ثقة (99 (9 , •) ماعدا في مؤهل الأب والإقامة مع الوالدين فكانت (90, • • ) أما ترتيب الطفل فلم يكن داعن دال. - هناك ارتباط دال بين العنف والخصائص النفسية عند درجة ثقة (99 (9 . •) ماعدا النظرة السلبية للذات كانت على درجة تقة (90, • •).

وتعتبر هذه الدراسة من الدراسات ذات الصلة الغير مباشرة بموضوع الدراسة حيث استفاد

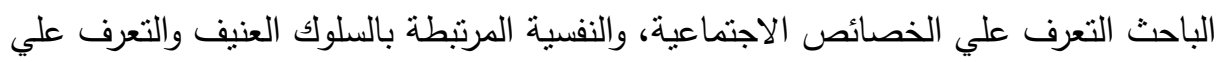
استمارة الاستبيان ومقياس العنف من إعداد الباحث ووجود ارتباط دال بين العنف والسمات ولفه النفسية، والاجتماعية للشخص العنيف.

r - على عزمي عبد السلامب I ـ ץ: السمات الاجتماعية والنفسية المرتبطة بالمحافظة على الممتلكات العامة داخل الجامعات المصرية.

هافت الاراسة: هدفت الدراسة على التعرف على السمات الاجتماعية والنفسية المرتبطة

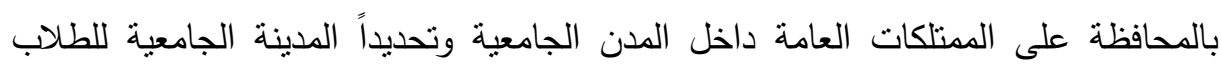
بجامعة عين شمس، و تكونت عينة الدراسة من عدد (. . ب) طالب من طلاب المدينة الجامعية بجامعةعين شمس والمقيمين بها .ولقد استخدم الباحث المنهج الوصفي التحليلي

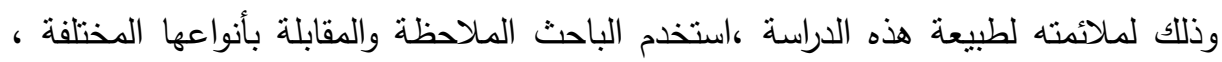
كما استخدم الباحث 
صحيفة الاستبيان لجمع البيانات من مجتمع البحث الذى خطط له وهو المدينة الجامعية

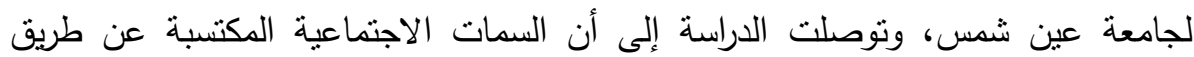

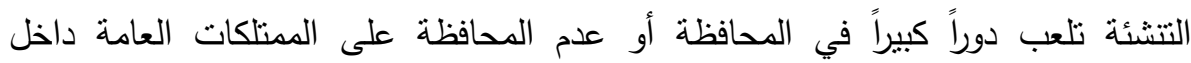

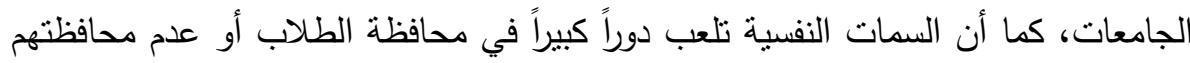
على الممتلكات العامة داخل الجامعات وذلك من خلال التتشئة النفسية السليمة داخل الاسرة والجو الأسرى السليم والصحة النفسية السليمة، وأوضحت نتائج الدراسة أن عدم وجود العقوبات والجزاءات المناسبة والرادعة تؤدى ببعض الطلاب إلى عدم المحافظة على الى الى

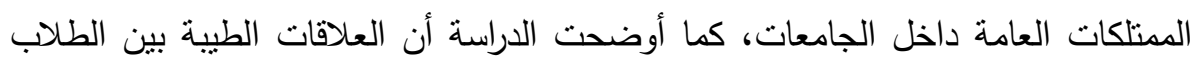
والمشرفيين الإداريين بالمدينة الجامعية تؤدى إلى الحفاظ على الممتلكات العامة داخل الجامعة ، وأنشارت الدراسة إلى وجود علاقة ارتباطية دالة احصائياً بين السمات النفسية والاجتماعية لدى الطلاب والمحافظة على الممتلكات العامة داخل المدينة الجامعية، وأوضحت الدراسة أن لرعاية الثباب بالجامعات دوراً كبيراً في الحفاظ على المثنلكات العامة

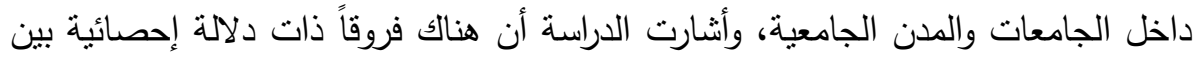
أراء طلاب المدينة الجامعية طبقاً لنوع الكلية وطبقاً للمستوى الاجتماعي والاقتصادي.

\section{Vergès -Belmin,V.,: Illustrated Glossary on Stone Deterioration}

Patterns. English-. French Version , Paris ICOMOS - ISCS, 2008.

تتاولت الدراسة محاولات السلوكيات الخاطئة والخاصة بالتلف البشرى المتمثل في حدوث السرقات، والتخريب المتعدد لبعض اللوحات الصخرية، وكذلك إعادة استخدام مواقع المحاجر

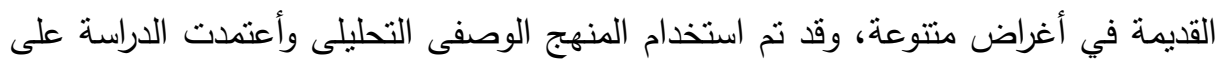

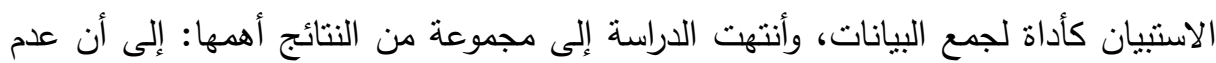

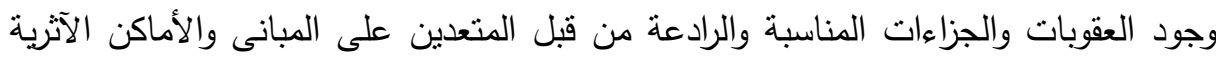
يؤدى إلى تخريبها وتلفها، بالإضافة إلى سهولة سرقتها، كما اوضحت الدراسة إلى انه كلما ذات الوعى بالآثز ، كلما ساعد ذلك على المحافظة عليه من التلف والتخريب والسرقات، سواء للمبانى أو اللوحات الصخرية الموجودة بالمعابد والأماكن الآثرية.

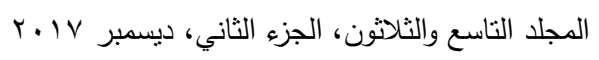


El-Gohary, M.A.,: Air Pollution and Aspects of Stone Degradation " UmayyedLiwanP. 4, 2008Amman Citadel as Case Study" . Journal of Applied ScienceResearch .

هدفت الدراسة إلى التعرف على أسباب وعوامل تعدد مصادر تلوث الهواء الجوي مابين

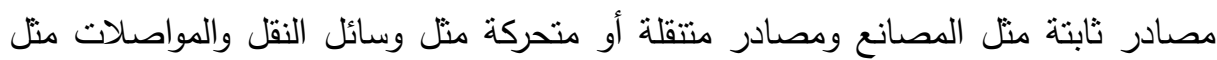
السيارات والتي يتتوع التلف الناتج عنها بالأسطح، والتى تعمل على تلوث الغلاف الجوى، وما تؤدية من تأثثرات ضارة على صحة الأنسان وكذللك على العاملين فيها وايضاء المقيمين حول

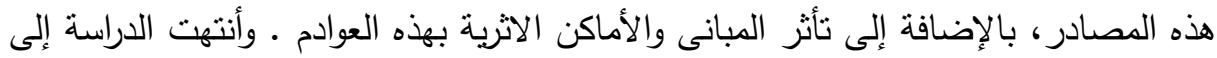

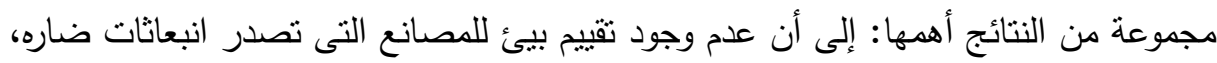

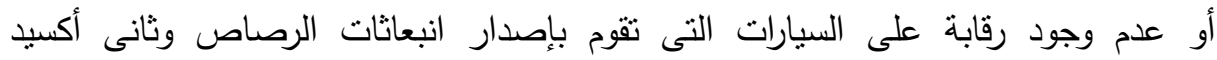
الكربون، ما يمثل ضرر بالغ على صحة الأنسان وكذلك الضرر بالأماكن الآثرية.

- Bloxam, E.,: Re-use, Looting and Vandalism of Ancient Quarries. Quarryscapes Conservation of:Stone Quarry Landscapes in the Eastern Mediterranean. AncienGeological Survey of Norway, 2007.

تتاولت الدراسة مظاهر التلف الثنائعة بالأسطح الأثرية، والناتجة عن الأنشطة البشرية

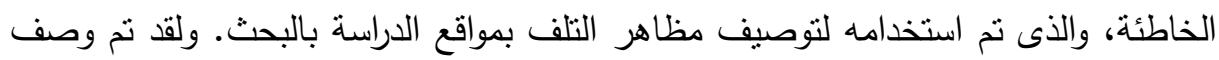
ما حدث في هذه الفترة عن طريق اللصوص والذي يثير الرعب في نفوس الأثريين اليوم.أن هؤلاء اللصوص قاموا بحملات تدمير كبيرة لمعابد الكرنك. ويصف » جاك ريفود 《 ما حدث في تلك الفترة عندما يتحدث عن وصف أثار طيبة " إن هذه الأحداث تضع القارئ اليوم

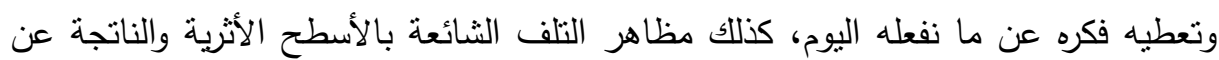
الأنشطة البشرية الخاطئة والذى تم استخدامه لتوصيف مظاهر التلف بمواقع الدراسة بالبحث. 


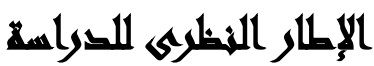

النظريات المفسرة للاراسة:

نظرية الأنماط: حاولت نظريات الأنماط تصنيف شخصيات الناس إلى أنماط، والنمط يجمع الصفات التي تكونت في مستهل حياة الفرد ولا تخضع لتغيير كبير، وعلى ذلك فنمط لتصني الثخصية يدل على جوهر الثخص. نظرية أبقراط: وهي من أقدم النظريات في هذا المجال إذ وضعها أبقراط في القرن الخامس

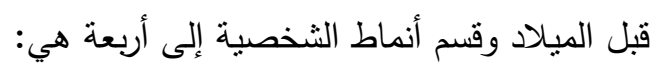

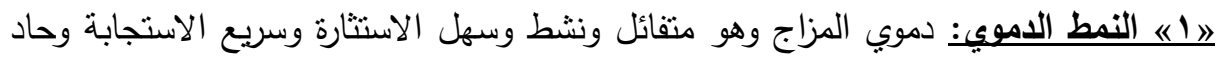

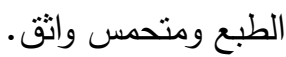
॥بإالنمط البلغمي: بلغي المزاج وهو منتائم ومنطوي ومكتئب وهابط النشاط بطيء التفكير متأمل. ״ب النمط الصفرلوي: صفراوي المزاج وهو سريع الانفعال وغضوب وعنيد وطموح.

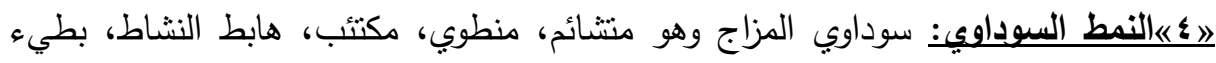

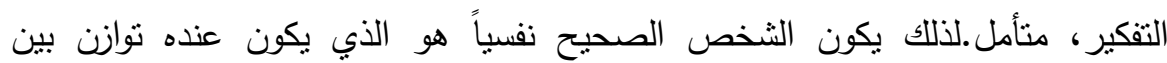

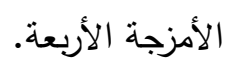

\section{نظريات السمات الشخصية}

تعريف السمة: يعرف Guilford السمة "بأنها أية طريقة متميزة ثابته نسبياً بها يتميز الفرد عن غيره من الأفراد"

ويبدو أن تعريف "جليفورد" تعريف واسع جداً وأعم من التعريفين الآخرين، ويمكن تطبيقه

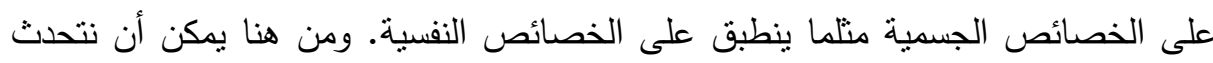

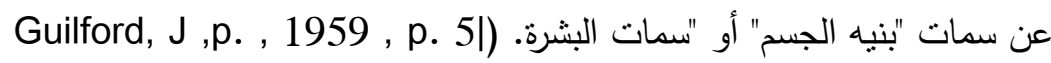


* أهم مفاهيم نظرية السمات:

1-الشخصية Personality: حسب هذه النظرية عبارة عن نظام يتكون من مجموعة سمات

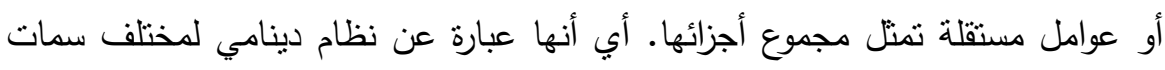

الشخصية.

r-السلوك: تفترض النظرية أن سلوك الإنسان يمكن أن ينظم بطريق مباشر، وأنه يمكن قياس السمات والعوامل المحددة لهذا السلوك باستخدام الاختبارات، والمقاييس للوقوف على لهى

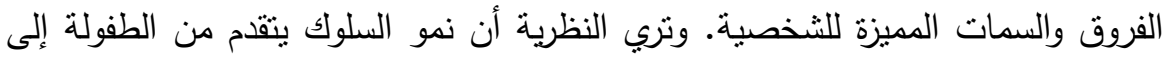

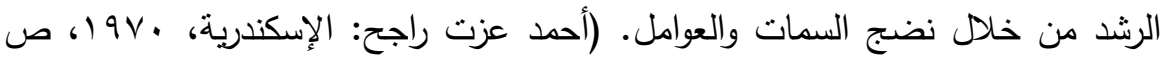

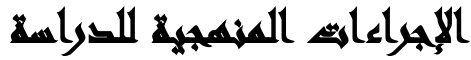

نوع الدراسة والمنهج المستخدم: ندخل هذه الدراسة في نطاق الدراسات الوصفية لأنها أنسب الدراسات ملائمة لطبيعة الظاهرة المدروسة، حيث يتضمن هذا النوع من الدراسات دراسة الحقائق المتعلقة بطبيعة الظاهرة، كما اعتمدت هذه الدراسة على منهج المسح الاجتماعي بالعينة حيث يعتبر منهج المسح الاجتماعي من المناهج المناسبة للاراسات

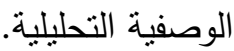

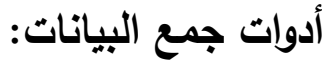

- مجتمع الاراسة: مدينة الأقصر لكى تجرى بها الدراسة الميدانية، تجميع قدر من البيانات المتصلة بالأنماط السلوكية الخاطئة تجاه المباني والأماكن الأثرية، وذلك بما يخدم

$$
\text { أغراض الدراسة. }
$$

استمارة استبيان، والمقابلة الثخصية للدراسة المتعمقة، وأداة الملاحظة كأدوات لجمع البيانات - الاستبيان(Questionnaire): صياغة الأسئلة وعددها سنين سؤالاً، في شكل وأسئلة مقننه، وبلغة سهلة واضحة، كذللك تم ترتيبها بشكل منطقي، ليتواكب مع أهداف الدراسة،

$$
\text { وطبيعة الموضوع. }
$$

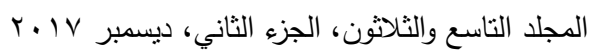




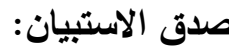

الصدق الظاهرى: بالنسبة إلى الاستبيان قام الباحثون فى إطار مراعاة الصدق الظاهرى

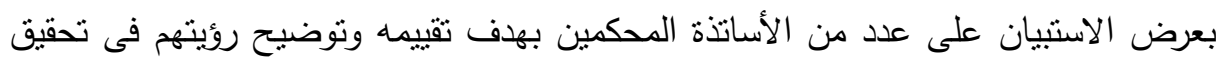

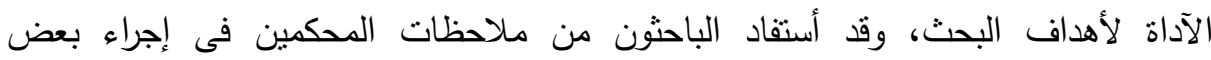
التعديلات على إستمارة الاستبيان قبل تطبيقها كحزف بنود أو إضافة بنود جديدة.

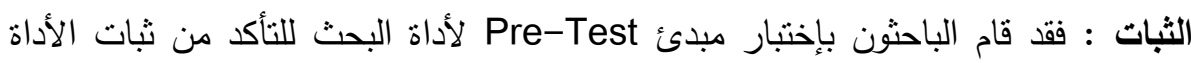

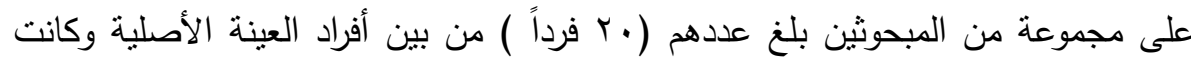
الغالبية العظمى من الإستجابات مطابقة للأسنبيان الأصلى، وقد أدى ذلى ذلك كله لهن إلى إنى

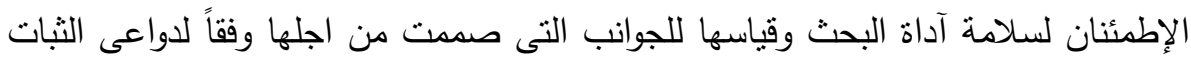

والصدق المنهجيين.

\section{صدق الإتساق الداخلي للاستيبان:}

- تم حساب معاملات ارتباط كل بعد من أبعاد الاستبيان بالدرجة الكلية للاستبيان والتي نتجت عن تطبيق الاستبيان على عينة مبئية بلغ عدد أفرادها (.0) فرد من أفراد عينة الدراسة، وقام الباحثون بحساب صدق الإتساق الداخلي كالآتي:

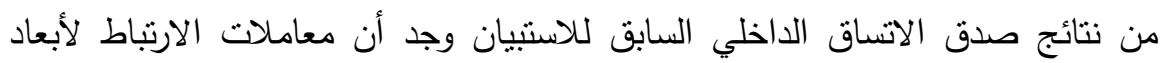

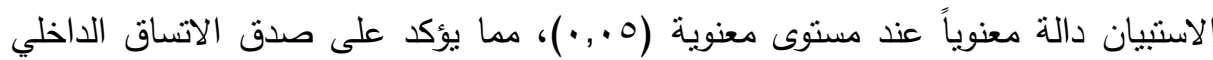

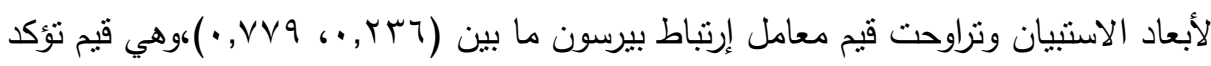

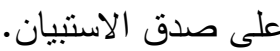
ثبات الاستبيان: للتحقق من ثبات الاستبيان استخدم الباحثون معادلة ألفا كرونباخ (Alpha Cronbach)، وظهرت معاملات الثبات الناتجة باستخدام هذه المعادلة، حيث وجد أن قيم معاملات الثبات لأبعاد الاستبيان قيم مقبولة تراوحت قيم معامل الثبات بين

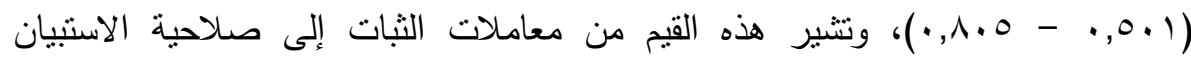
للتطبيق وامكانية الاعتماد على نتائجه والوثوق به، وكانت قيمة ألفا لإجمالي الاستبيان

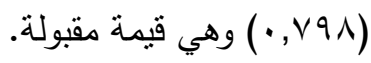




\section{مجالايت السراسمة}

أ- المجال الجغرافي: ويقصد بالمجال الجغرافي هو النطاق المكاني لإجراء الدراسة، وفى

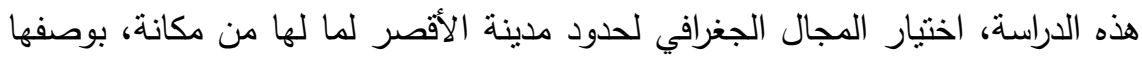

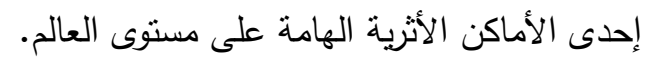

ب- المجال البشرى: ويقصد بالمجال البشرى هو جمهور الدراسة وهم فئات الثباب في

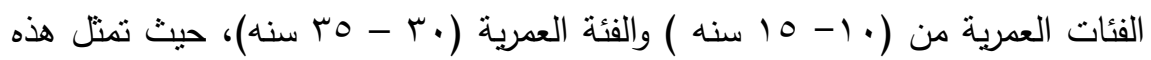
الفئة عينة الدراسة. ج- المجال الزمني: استغرقت الدراسة الميدانية قرابة الثلاثة أنثهر، ابتداء من شهر يناير

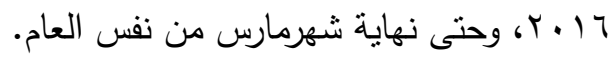

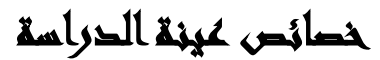

جدول(1): الأعداد والنسب لعينة الدراسة تبعاً للمتغيرات الديموجرافية

\begin{tabular}{|c|c|c|c|}
\hline ألثسبة & العدد & المتفِرِك & 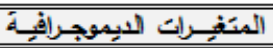 \\
\hline o. & 0. & Ji & \multirow{3}{*}{ 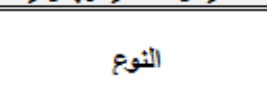 } \\
\hline 0. & 0. & آتثخث & \\
\hline $1 \ldots$ & $1 \ldots$ & الإجمالّي & \\
\hline$\varepsilon$ & $\varepsilon$ & من · إلمى10 & \multirow{3}{*}{ الفئة العمرية } \\
\hline 7. & 7. & من • إلهىه & \\
\hline $1 \ldots$ & $1 \ldots$ & الإجمالى & \\
\hline 4 & $\pi$ & أعزيب & \multirow{3}{*}{ الحالة الاجنماعِة } \\
\hline rA & TA & متَزوج & \\
\hline $1 \ldots$ & $1 \ldots$ & الإجمالي & \\
\hline$\varepsilon \wedge$ & $\varepsilon \wedge$ & طالب & \multirow{7}{*}{ المهنة } \\
\hline$\varepsilon$ & $\varepsilon$ & عاهل & \\
\hline$r$ & $r$ & فظى & \\
\hline$\Lambda$ & $\Lambda$ & موظف & \\
\hline $1 \varepsilon$ & $1 \varepsilon$ & أخصائتى & \\
\hline r & r & أخضصائي أثَّار & \\
\hline$\ldots$ & $1 \ldots$ & الإجمالى & \\
\hline+1 & ri & بعرَأ وريكتب & \multirow{6}{*}{ المستَقى التَعلِيمى } \\
\hline 11 & 11 & إعداديِة & \\
\hline 17 & 17 & مؤهل منَوبط & \\
\hline \&1 & \&1 & هؤهل عالّي & \\
\hline 1 & 1 & درإعات عليا & \\
\hline $1 \ldots$ & $1 \ldots$ & الإجمالى & \\
\hline
\end{tabular}


وصف الجدول: نبين من الجدول السابق للأعداد والنسب لعينة الدراسة تبعاً للمتغيرات

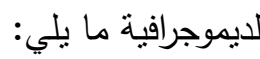

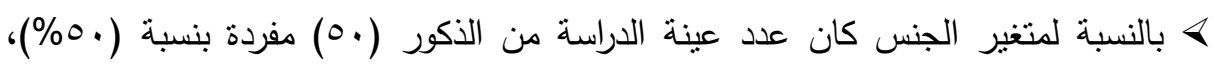

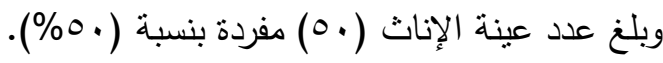

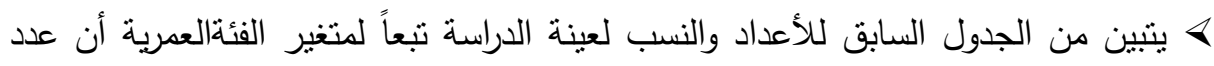

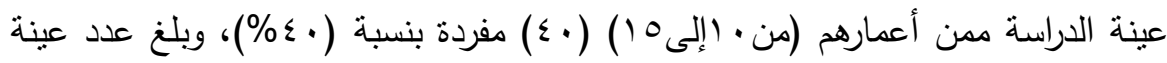

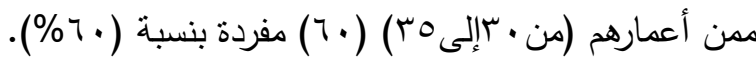

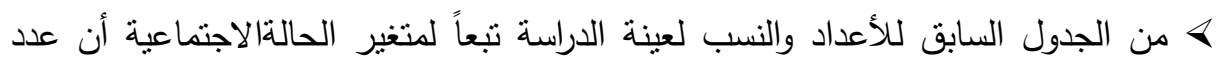

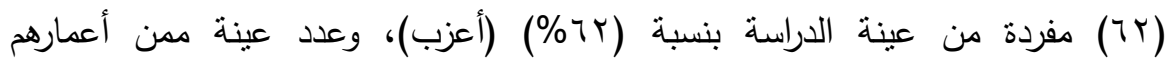

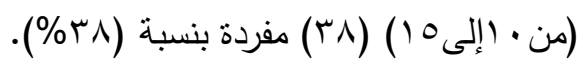

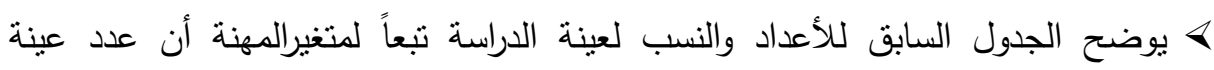

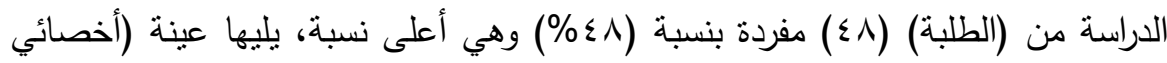

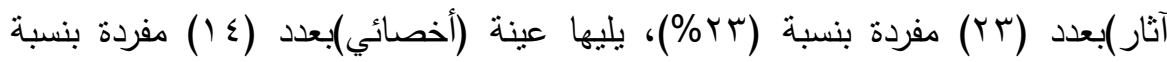

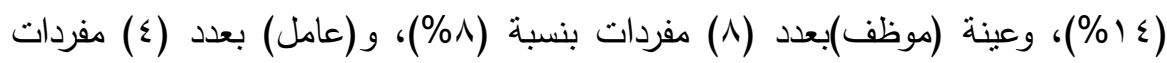

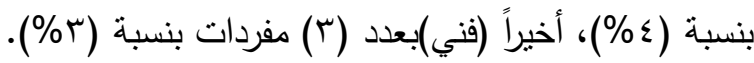

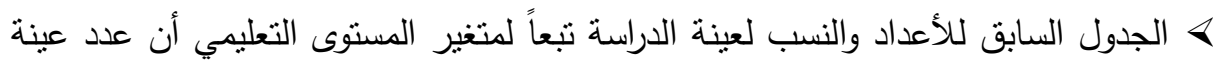
الدراسة ممن (مؤهل عالي) (1) مفردة بنسبة (1 (1\%) وهي أعلى نسبة، يليها عينة (يقرأ

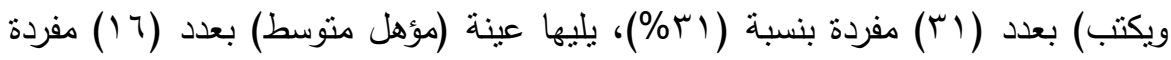

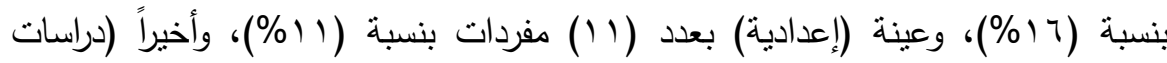
عليا) بعدد مفردة بنسبة (1\%). تفسير وتحليل الجدول: حاول الباحث أن تمثل هذه العينة قدر الإمكان مجتمع البحث من بن سكان وأهالي منطقة ومكان الدراسة والبحث وهي محافظة ومدينة الأقصر . 
حساب الثبات والصدق لاستبيان قياس السلوك الاجتماعي: حساب ثبات الاستبيان: للتحقق من ثبات الاستبيان استخدم الباحث معادلة ألفا كرونباخ (Alpha Cronbach) المعادلة. جدول رقم(ץ): ثبات العبارات لأبعاد استمارة استبيان قياس السلوك الاجتماعي الخاطئ على المباني والمعابد والمواقع الأثرية.

\begin{tabular}{|c|c|c|}
\hline معامل ثبات ألفا & العبارات & أبعاد الاستبيان \\
\hline$\cdot, \Lambda \cdot r$ & 1. & عليها في والأماكن والأثرية. والسرقة وتسلق المباني والجلوس \\
\hline$\cdot, \mathrm{V} \circ \mathrm{r}$ & 1. & البناء والتعدي علي المباني الأثرية في الأماكن الأثرية. \\
\hline$\cdot, \vee \vee 91$ & $1 \cdot$ & الأكل وإلقاء المخلفات في الأماكن الأثرية. \\
\hline$\cdot, \wedge \leq \mu$ & 1. & حرق مخلفات القمامة والمحاصيل الزراعية ومياه الترع. \\
\hline$\cdot, \wedge \cdot \wedge$ & $1 \cdot$ & في الأماكن الأثرية. والحيوانات والمعدات النقيلة وإقامة الحفلات \\
\hline$\cdot, \vee>0$ & 1. & 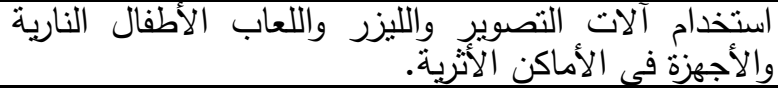 \\
\hline$\cdot, 9 \leq Y$ & 7. & إجمالى استييان \\
\hline
\end{tabular}

وصف الجدول: يوضح الجدول أبعاد دراسة أنماط السلوك الاجتماعي الخاطئ ومدي نأثيره علي المعابد والمباني الأثرية بمنطقة الأقصر مكان البحث والدراسة.

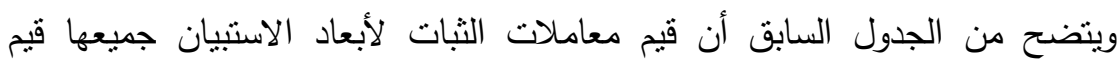

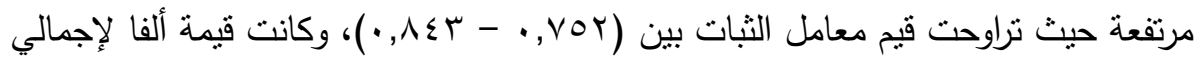

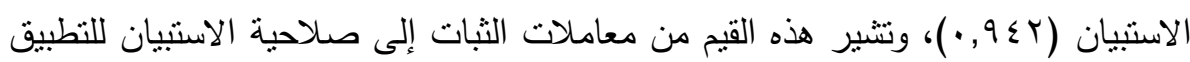
وإمكانية الاعتماد على نتائجه والوثوق به. تفسيروتحليل الجدول: من خلال أراء المبحوثين في بعد( حرق مخلفات القمامة والمحاصيل

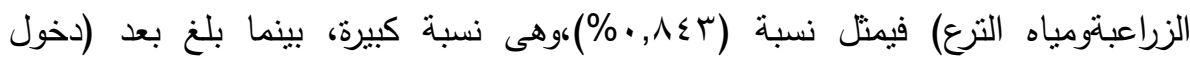
السيارات والحيوانات والمعدات الثقيلة وإقامة الحفلات في في الأماكن الأثرية.) نسبة(^ • ^, • \%)، وبلغت نسبة (الكتابة والخد والهدم والسرقة ونسلق المباني والجلوس

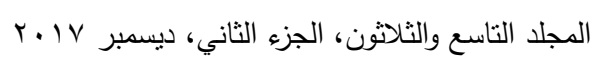


عليها في الأماكن الأثرية) نسبة(r • ^, • \%)، وجاء البعد الخاص (الأكل وإلقاء المخلفات في

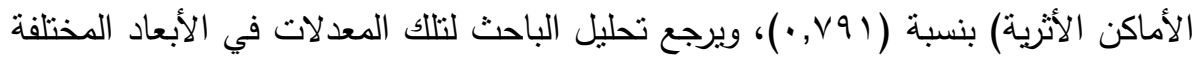

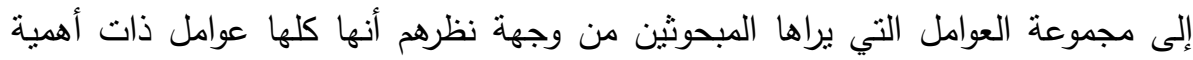

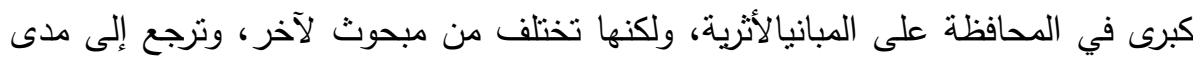

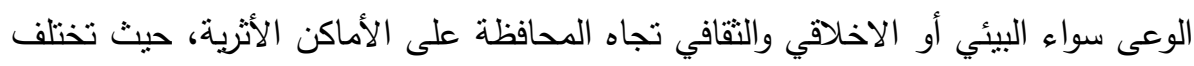
درجة السلوك الخاطئ في المحافظة على تلك الممتلكات من شخص إهـ إلى آخر . جدول(r): اختبار ت T-Test لحساب الفروق بين منوسط درجات عينة الدراستتبعًا لمتغير النوع لعينة (الصغار) من المرحلة العمرية (•إ-10 عام) لأبعاد استمارة استبيان قياس السلوك الاجتماعي الخاطئ على المباني والمعابد والمواقع الأثرية.

\begin{tabular}{|c|c|c|c|c|c|c|}
\hline \multirow{2}{*}{ 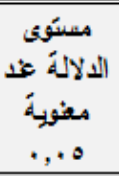 } & \multirow[b]{2}{*}{ قِيمة (ت) } & \multicolumn{2}{|c|}{ 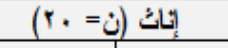 } & \multicolumn{2}{|c|}{ ذكور (ن) = r r) } & \multirow[b]{2}{*}{ أبعاد الأنتيّيان } \\
\hline & & المعِارب & المنتوبط & المعِيارب & المنتوسط & \\
\hline غخر دل & $1, \vee\urcorner$ & $\Psi, £ \vee$ & Q & $\{, \infty 0$ & זr, & 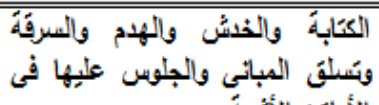 \\
\hline غير دل & $1, r \vee \wedge$ & $\Psi, v \varepsilon$ & $r \cdot, 1$. & $0, \cdot v$ & $+1,9$. & 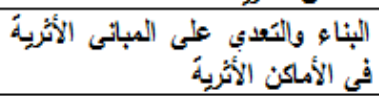 \\
\hline ثخر دل &., $9 \div 9$ & $\{, \mathfrak{1}$ & iv, .. & $\varepsilon, .9$ & $11, t_{0}$ & 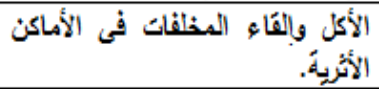 \\
\hline دل & $r, \cdot v^{T}$ & $\mathfrak{\varepsilon , \wedge \wedge}$ & IV,, . & $£, \diamond \mathrm{V}$ & 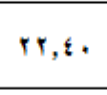 & 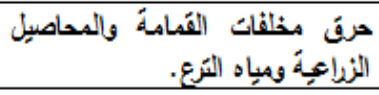 \\
\hline غخر دل & 1, 1, 1, & $\{, 1 \varepsilon$ & $r \cdot, 9$. & $0, \wedge 1$ & rr, & 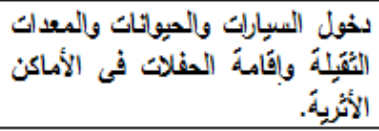 \\
\hline غخِ دل & $1, \leqslant \leqslant \leqslant$ & r,iv & 19,10 & 0,11 & $r 1, r$. & 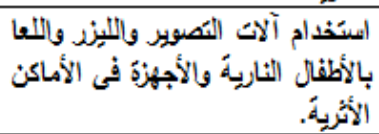 \\
\hline J & r,.or & 19,10 & $110, r$. & $r \varepsilon, 0 \wedge$ & $1 \times 9, \wedge$. & إجماللي الاعنيّيان \\
\hline
\end{tabular}

وصف الجدول : من الجدول السابق لحساب الفروق بين متوسط درجات عينة الدراسة تبعاً

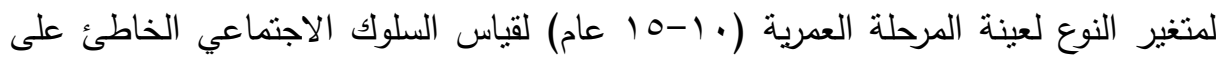
المباني والمعابد والمواقع الأثرية يتضح الآتي:

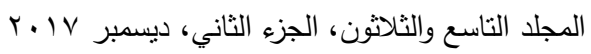


ه وجود فروق ذات دلالة إحصائية بين متوسط درجات عينة الدراسة تبعاً لمتغير النوع لعينة المرحلة العمرية (• (1-0 عام) لبعد حرق مخلفات القمامة والمحاصيل الزراعية ومياه

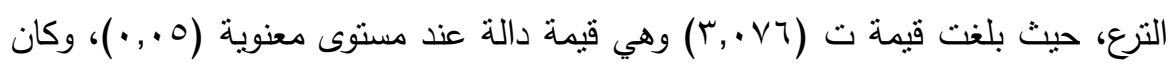

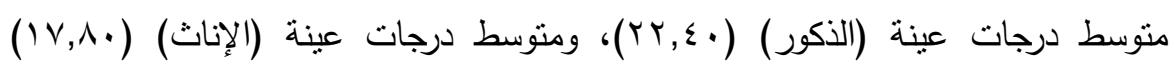

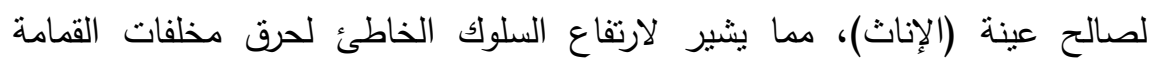
والمحاصيل الزراعية ومياه الترع لدي عينة (الذكور ) عن عينة (الإناث).

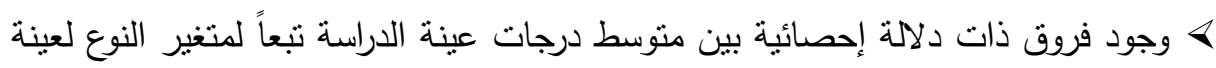

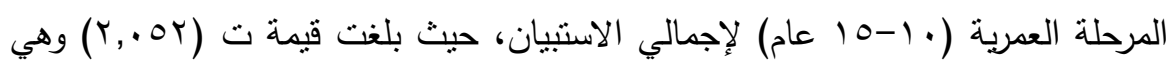

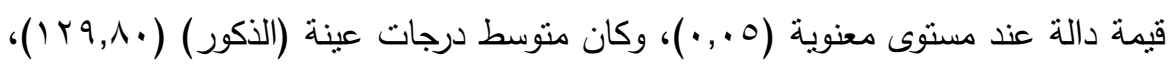

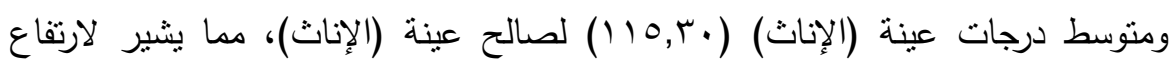
السلوك الخاطئ لدى عينة (الذكور) عن عينة (الإناث).

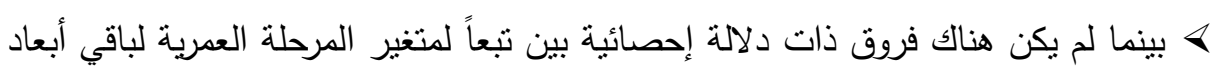
استمارة استبيان قياس السلوك الاجتماعي الخاطئ على المباني والمعابد والمواقع الأثرية

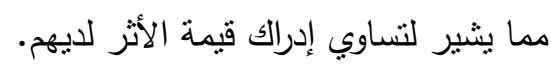

تفسير وتحليل الجدول: يتضح من الجدول السابق أن هناك تأثنر على المعابد والمباني

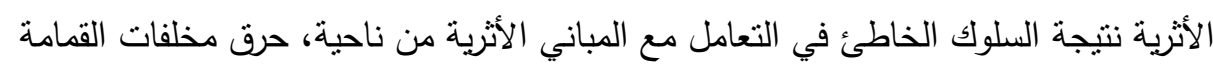

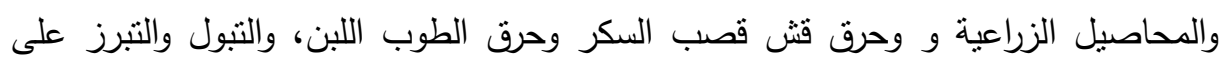

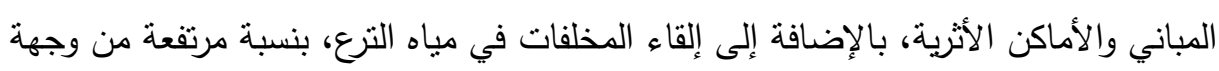

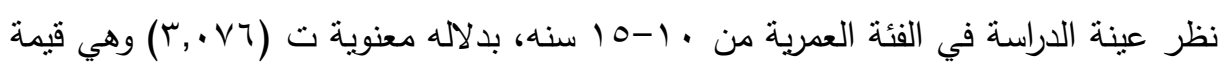
دالة عند مستوى معنوية (0. , •). 
جدول(؛): اختبار ت T-Test لحساب الفروق بين منوسط درجات عينة الدراسة تبعًا لمتغير النوع لعينة (الكبار) من المرحلة العمرية (•r-هب عامدام) لأبعاد استمارة استبيان قياس السلوك الاجتماعي الخاطئ على المباني والمعابد والمواقع الأثرية.

\begin{tabular}{|c|c|c|c|c|c|c|}
\hline \multirow{2}{*}{ عندمعنوية الالالة } & \multirow{2}{*}{ قيمة } & \multicolumn{2}{|c|}{ إناث (ن= · r r) } & \multicolumn{2}{|c|}{ ذكور (ن= ·r) } & \multirow[b]{2}{*}{ أبعاد الاستبيان } \\
\hline & & الالمعراف & المتوط & الانحراف & المتوسط & \\
\hline غير دال & $\cdot, 701$ & $\varepsilon, .9$ & $1 \wedge, 0$. & r,vo & $I V, \lambda$. & 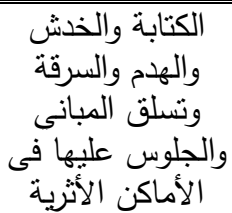 \\
\hline 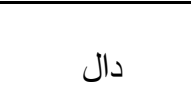 & $r, I V Y$ & r,VA & $19,0 \mathrm{~V}$ & $\varepsilon, \cdot 7$ & $I V, r V$ & 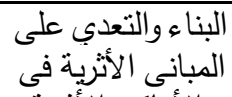 \\
\hline غير دال & $1,1 \wedge 4$ & $r, \wedge q$ & $10,0$. & $r, Y v$ & $1 \leqslant, \varepsilon$. & الأمخلفات فألقى الأثى \\
\hline 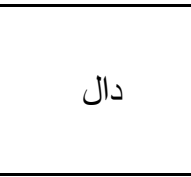 & $r, \mu r$. & $\varepsilon, Y_{O}$ & $r \cdot, \cdot V$ & $r, 74$ & $17,7 \mathrm{~V}$ & 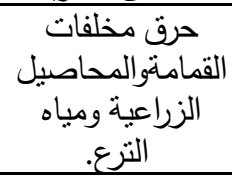 \\
\hline غير دال & $\cdot$, Or & $7, \ldots$ & $r 1,0$. & $\{, 0\}$ & $r \cdot, V V$ & 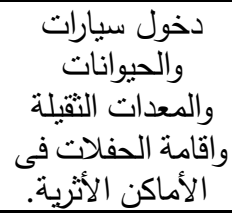 \\
\hline غير دال & $1, \varepsilon \vee 9$ & $r, T V$ & $r_{1, \cdot V}$ & $\varepsilon, r \varepsilon$ & 19,0 r & 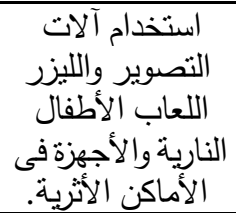 \\
\hline غير دال & $1,9 \leqslant V$ & $r \cdot, r_{0}$ & $117, r$. & $\mid \Lambda, 1 \varepsilon$ & $1,7,04$ & إجمالي الاسنبيان \\
\hline
\end{tabular}

تفسير وتحليل الجدول: يتضح من الجدول السابق أن هناك تأثثر على المعابد والمباني الأثرية نتيجة السلوك الخاطئ في التعامل مع المباني الأثرية من ناحية، حرق مخلفات القمامة والمحاصيل الزراعية وحرق قش قصب السكر وحرق الطوب اللبن، والتبول والتبرز 
على المباني والأماكن الأثرية، بالإضافة إلى إلقاء المخلفات في مياهالتزع، بنسبة مرتفعة

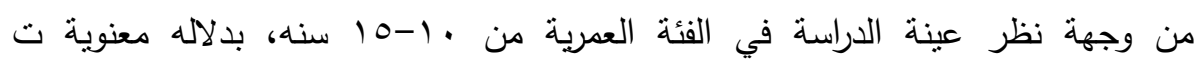

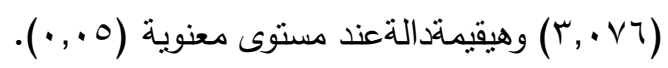

وصف الجدول: من الجدول السابق لحساب الفروق بين منوسط درجات عينة الدراسة تبعاً

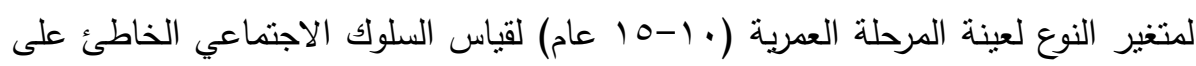

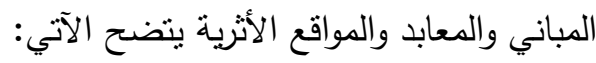
ه وجود فروق ذات دلالة إحصائية بين متوسط درجات عينة الدراسة تبعاً لمتغير النوع الاتئي

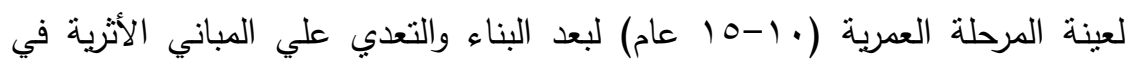

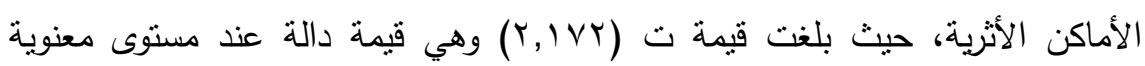

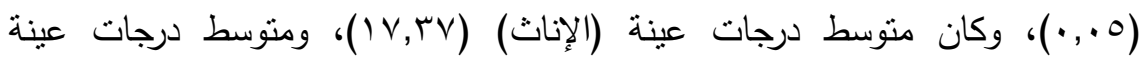

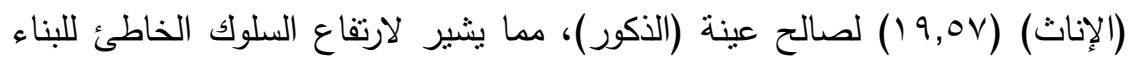

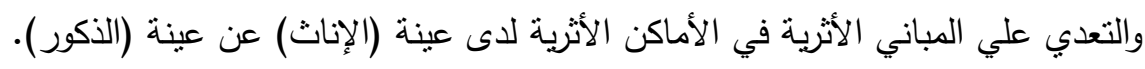

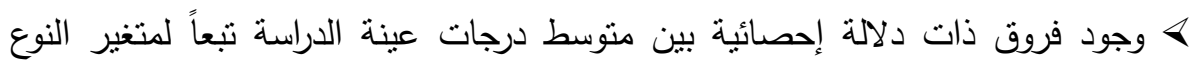
لعينة المرحلة العمرية (• (1-1 عام) لحرق مخلفات القمامة والمحاصيل الزراعية ومياه

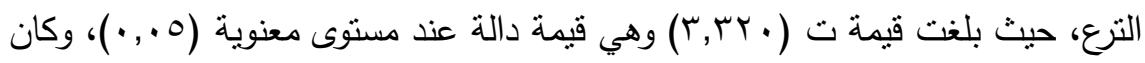

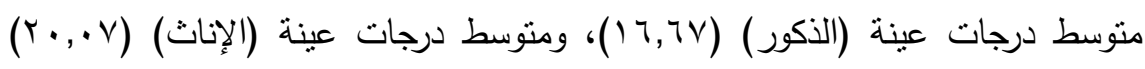

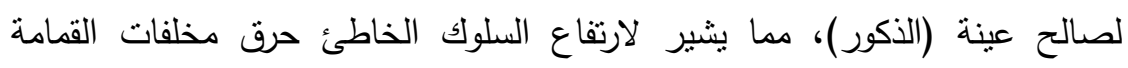
والمحاصيل الزراعية ومياه الترع لدى عينة (الإناث) عن عينة (الإناث).

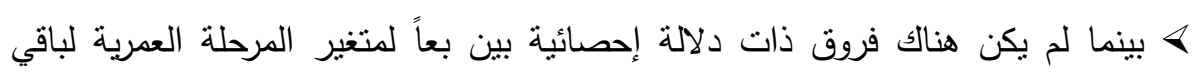

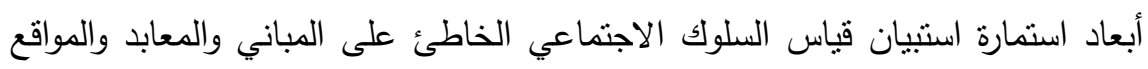
الأثرية مما يشير لنساوي إدراك قيمة الأثر لديهم.

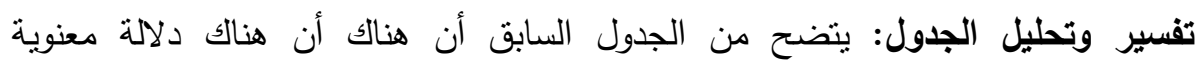
للبمحوثين حول ارائهم في البعد الخاص (حرق مخلفات القمامة والمحاصيل الزراعية ومياه

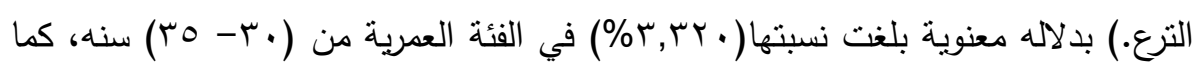


جاء البعد الثاني والخاص (البناء والتعدي علي المباني الأثرية في الأماكن الأثرية) بنسبة ( r, l V) )، ويرجع ذلك إلى أراء المبحوثين في ارتفاع ظاهرة التعدي على الأراضي الأثرية

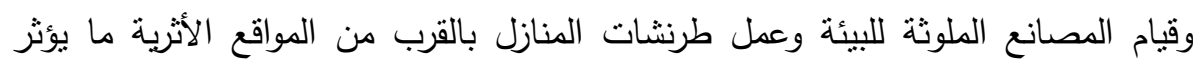

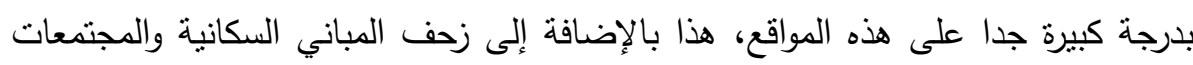

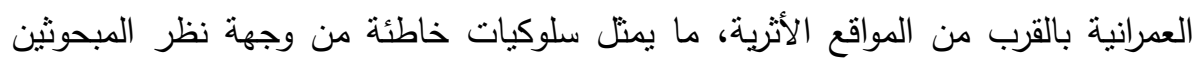
والمقيمين بالقرب من هذه الأماكن.

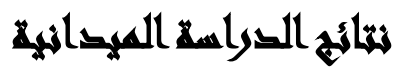

خلصت الاراسة لعدداً من النتائج : من أبرزها أن هناك فروقاً ذات دلاله إحصائية بين أراء المبحوثين من الثباب في مجتمع الدراسة حول أنماط السلوكيات الخاطئة تجاه الأماكن الأثرية في مجتمع الدراسة. *وفى رأى المبحوثين أن سبب تلك السلوكيات الخاطئة تجاه المباني والمواقع الأثرية عدم وجود الوعى الكافي تجاه المحافظة على هذه المباني الأثرية والتي تعد ممنلكات عامه.

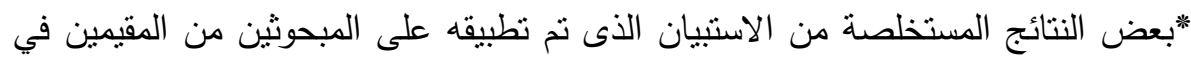

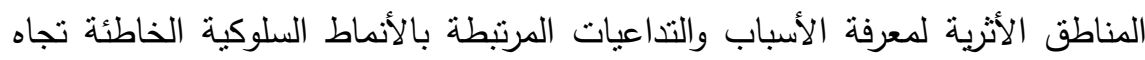

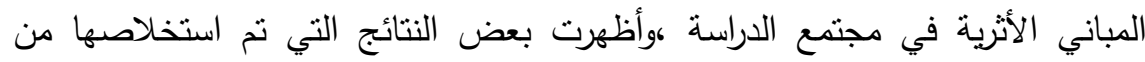
الاسنبيان:

* أظهرت نتائج الدراسة أن نسبة كبيرة من المبحوثين لا نوافق على السلوكيات الخاطئة التي تمارس تجاه المباني والمواقع الأثرية. *بيت الدراسة أن من الأسباب الاجتماعية التي تؤدى إلى التعدي على المواقع التع الأثرية

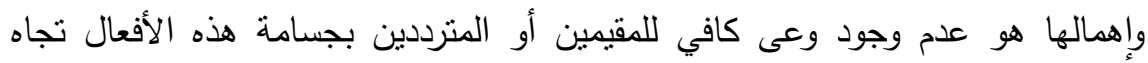

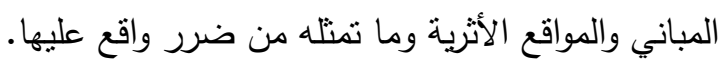




\section{همبرداهي التراسما}

\section{أولاً: نتائج الاراسة:}

- القيام بأعمال الحفائر والتتقيب في المواقع الأثرية، العثور على بعض المقتتيات والآثار المكتشفة والتي ينت والعمل على حفظها، وتسجيلها في سجلات تخص المنطقةالأثرية. - القيام بأعمال الترميم والصيانة في المواقع المختارة بالبحث سواء للمباني المشيدة بالحجر

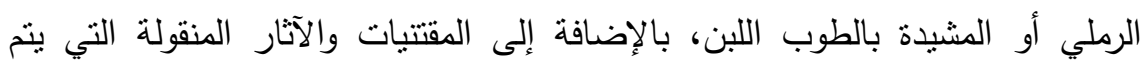
الكثف عنها أثثاء أعمال الحفائر وتجهيز إحدى المواقع منها لافتتاحها للزيارة أمام الزائرين.

- اختيار بعض الآثار المكتشفة ذات القيمة الجمالية التي يتم العثور والكثف عنها أثناء أعمال الحفائر والتتقيب بعد الانتهاء من ترميمها وصيانتها، لعرضها بالمتاحف الإنهات الإقليمية

$$
\text { بالمحافظات أو في متاحف العاصمة. }
$$

- التقدم في مجال البحث والتنقيب علي الآتار المكتشفة نتيجة التطور العلمي والتكنولوجيا الحديثة من خلا الأجهزة الحديثة، وكذلك أعمال التزميم والصيانة. - تتظيم وتتسيق مع إحدى المدارس واصطحاب مجموعة من التلميذ لزيارة إحدى المواقع المختارة والقبام بالثرح لتاريخ الموقع وأعمال البعثة العلمية وأهم أهدافها وكيفية الحفاظ

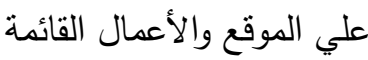
وتوجيه التلاميذ وزيادة الوعي وحثهم علي حماية وحفظ المواقع ومابها من مباني تاريخية - استخدام الأجهزة والوسائل الحديثة أثناء أعمال الحفائر الأثرية، والترميم والصيانة والعلاج للمقتتبات الأثرية المكتشفة، وكذلك تطوير مجال البحث والنشر العلمي. - نقل السوق الذي كان يقام أمام مدخل معبد أرمنت والثوارع المحيطة بالمعبد.

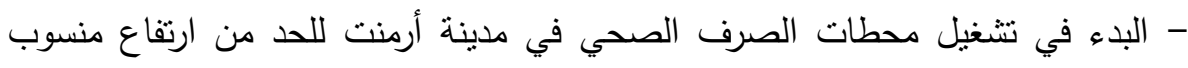
المياه السطحية والأرضية عن معبد أرمنت. 


\section{ثانيًا: توصيات البحث:}

- تفعيل دور وسائل الإعلام، العام منها والخاص من خلال بث برامج نوعية لمعرفة مدى

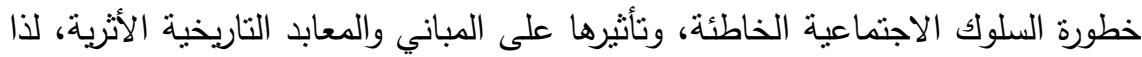

$$
\text { يجب تفعيل التوصيات الآتية. }
$$

- يجب الاهتمام بالمناطق الأثرية والمباني التاريخية وأعمال الترميم والصيانة للحفاظ عليها

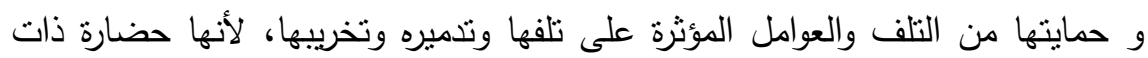

$$
\text { جذور عميقة وتراث ثقافي. }
$$

- يفضل أتباع الأساليب العلمية لنجاح عملية التنقيب والحفائر والكثف الأثري بالمواقع الأثرية لزيادة النشر العلمي الذى يثرى الأبحاث الأثرية على المستوى العالمي. - يجب دراسة التاريخ والأثار المصرية القديمة وتاريخ مصر الفرعوني في جميع مراحل التعليم من الحضانة حتى الجامعة، وتطويرها بأسلوب مبسط وسهل الفهم علي تلاميذ دريذ

$$
\text { المدارس. }
$$

- يجب انتشار التوعية الثقافية، ونشر الوعى والمعرفة بالتاريخ والحضارة المصرية القديمة التي علمت العالم، وزيارة المناطق الأثرية وعقد المؤتمرات الدولية والندوات العلمية لتوضيح الوعى الأثري وضرورة الحفاظ علي المواقع الأثرية.

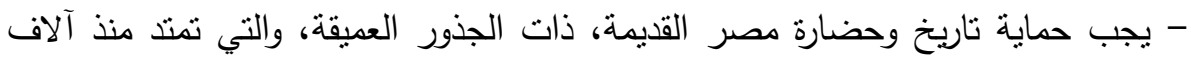
السنيين، والارتقاء بالوعي وزيادة الثقافة وتأهيل المناطق الأثرية، وانتشار التوعية الثقافية من خلالعقد المؤتمرات الدولية والندوات العلمية للتوعية الأثرية وضرورة الحفاظ بلهات عليها. - يجب الارتقاء بالمناطق السكنية والعمرانية المحيطة بالمباني والمعابد الأثرية وتطوير العشوائيات، والارتقاء بها وترميمها وصيانتها وتأهيلها. - يجب بناء أسوار حول المناطق الأثرية وإنارتها خاصةً القريبة من المناطق السكنية وحل ونل مشاكل الصرف الصحي والصرف الزراعي، وتغطية الترع الخاصة بالري الزراعي القريبة من المعبد، ونقل موقف السيارات الموجود والملاصق لمعبد أرمنت الأثرية. 


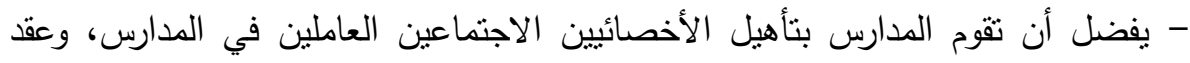
الندوات والمحاضرات والمناقثات المفتوحة وأهمية وأساليب النتشئة الاجتماعية السليمة الهينة وأثرها على التوافق النفسي للأبناء، لنشر الوعى داخل المدرسة والمؤسسات وأفراد الأسرة والمجتمع.

- يفضل التوعية من خلال البرامج الإعلامية والدينية عن أساليب التنشئة الاجتماعية

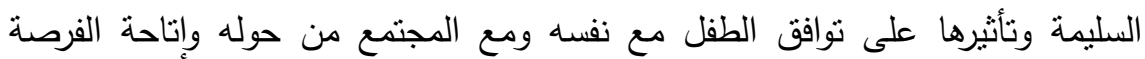

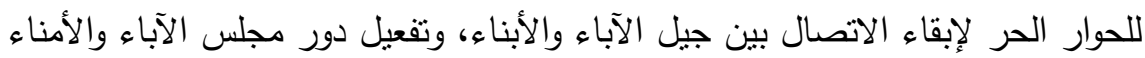
والمعلمين بالمدارس.

- ينبغي الارتقاء برفع ثقافة الأفراد بالمجتمع بأهمية المواقع الأثرية والتاريخية والتراث الحضاري لاى أفراد المجتمع منذ الصغر وكيفية المحافظة والاهتمام بالمواقع الأثرية كجزء من تاريخنا وتراثنا.من خلال وسائل الأعلام المختلفة، ووزارة الدولة لثنئون الآثار

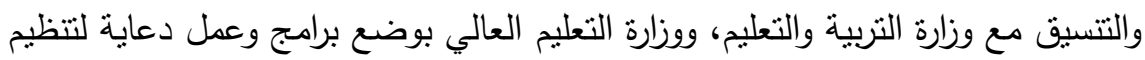

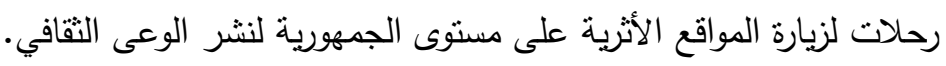

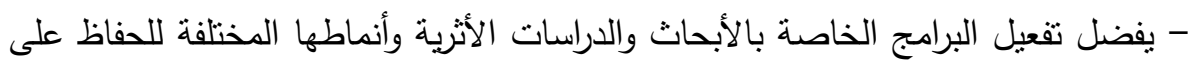
المباني الأثرية والحفاظ عليها من خلال الهيئات العلمية الدولية، وتتفيذ القوانين الخاصة ولاصنة بحماية التراث والمواقع والمباني الأثرية والتاريخية علي مستوى الجمهورية، وتذليل الصعاب، العراقيل أما البعثات العلمية. - يجب نتثيط وتفعيل التعاون الدولي والاشتراك في أعمال الترميم والصيانة للمواقع الأثرية

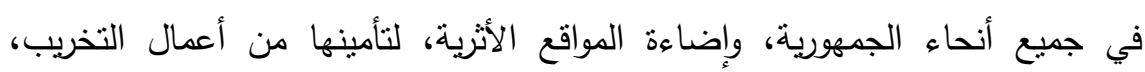
والنهب نتيجة للسلوك الاجتماعي الخاطئ.

\section{المراليع}

إبراهيم إسماعيل(910): الثباب بين التطرف والانحراف، مكتبة الدار العربية للكتاب،القاهرة.

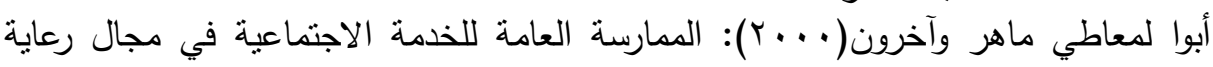

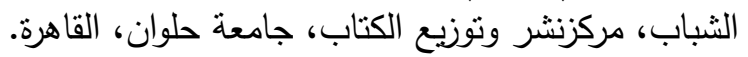

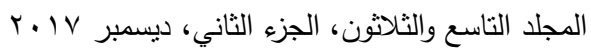




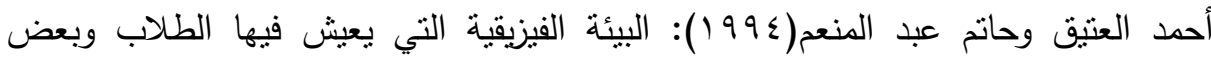

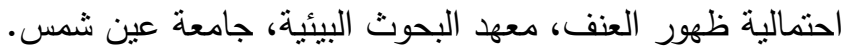

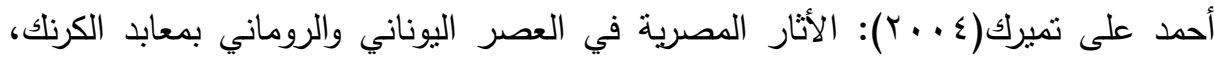

$$
\text { الأسكندرية. }
$$

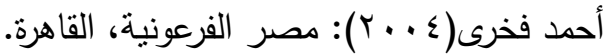

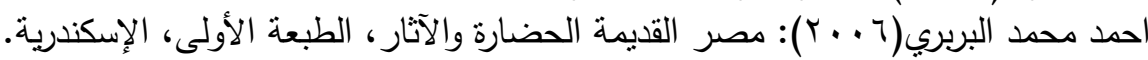

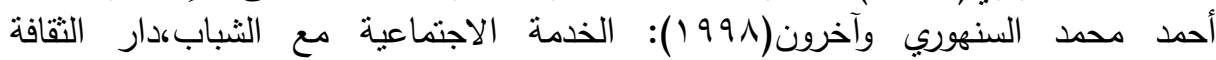
ل للنشروالتوزيع، القاهرة

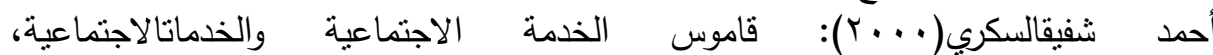
الإسكندرية،دارالمعرفة الجامعية.

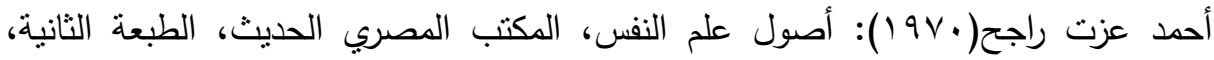

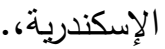

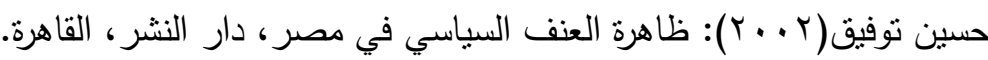

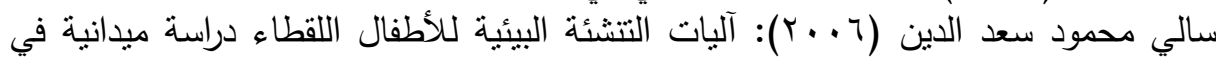

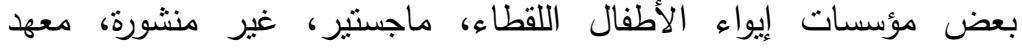

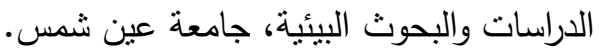

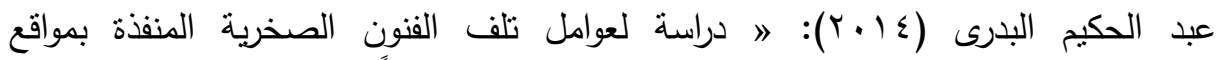

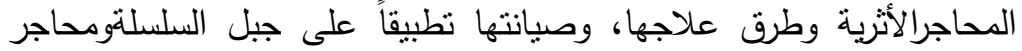

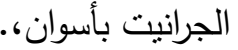

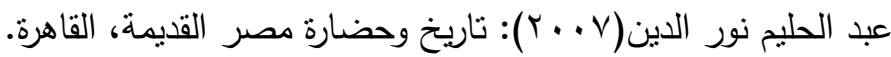

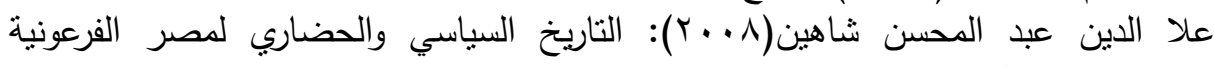

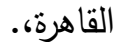

علي حسن(ب991): الموجز في علم الآتار ، الهيئة المصرية العامة للكتاب، القاهرة

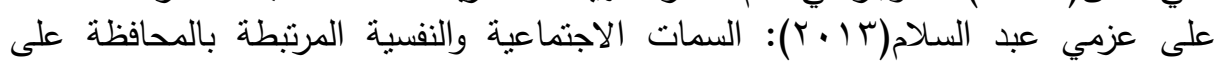
الممتلكات

العامة داخل الجامعات المصرية. فرج عبد القادر طه(999 (199): علم النفس وقضايا العصر ، معهد الدراسات والبحوث الإنسانية

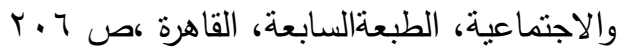

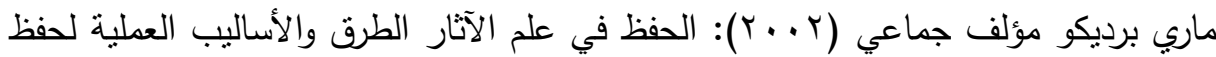

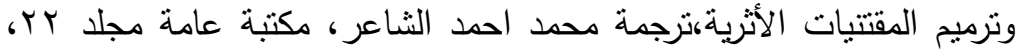
القاهزة

محمد زينهم(ץ + . ץ): دراسات في البيئة والفن، القاهرة. 
أحمد مصطفي العتيق وآخرون

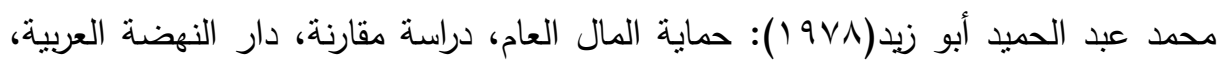
القاهرة.

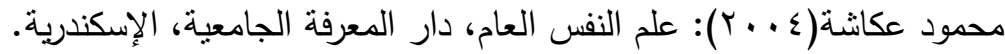

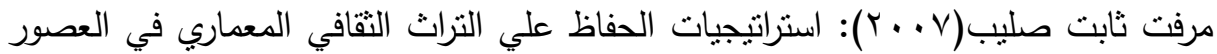

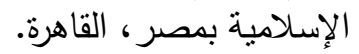

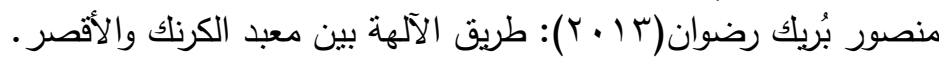

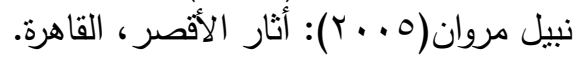

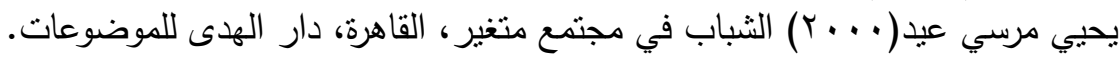

Bloxam, E.,: Re-use, Looting and Vandalism of Ancient Quarries. Quarryscapes Conservation of Ancient :Stone Quarry Landscapes in the Eastern Mediterranean. Geological Survey of Norway, 2007.

Christophe THIERS, Youri VOLOKHINE: Ermant Les cryptes du temple Ptolémaïque,2005

Claude TRAUNECKER, Jean-Claude GOLVIN :KARNAK Résurrection d'un site 1984.

El -Gohary, M.A., : Air Pollution and Aspects of Stone Degradation " Umayyed Liwan .Amman Citad el,. as Case Study " . Journal of Applied Science Research 2008.

Guilford, J ,p. ,Personality MC .Grow, , Hill Book Company , New York, 1959.

Ljaljevic, M.G.\&Vukojevic, J.B.,: Role of Fungi in Biodeterioration Process ofStone in Historic Buildings. Proc. Nat. Sci, MaticaSrpskaNovi Sad.N.116, 2009.

Vergès -Belmin,V.,: Illustrated Glossary on Stone Deterioration Patterns. English-. French Version ,Paris ICOMOS - ISCS, 2008. 


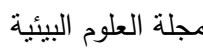

معهد الدراسات والبحوث البيئية - جامعة عين شمس لمس

\title{
A STUDY OF PATTERNS OF WRONG SOCIAL BEHAVIOR AND ITS IMPACT ON ARCHAEOLOGICAL TEMPLES AND BUILDINGS IN LUXOR AREA
}

\author{
El-Atiq, A. M. H. ${ }^{(1)}$; Ebeid, Magda, I. $^{(1)}$; Mohamed, M. A. ${ }^{(2)}$ \\ and Ismael, H. I. A. ${ }^{(3)}$
}

1) Institute of Environmental Studies \& Research, Ain Shams University 2) Faculty of Monuments, Cairo University 3) The Scientific French Institute for Eastern Monuments

\begin{abstract}
This thesis drives at examining patterns of wrong social behavior and its impact on temples and monumental buildings in Luxor area which owns the greatest and most important monumental buildings which is a national wealth and public property as it owns historical buildings, tombs, and unique monumental temples. Arabs call Luxor the city of palaces when they have seen Al-Karnack high temples, Luxor temple, and greatness of Egyptian ancient civilization; as Egypt owns third of the world ancient monuments most of them exists in Luxor city's two banks of the river where the greatest temples of nobles and honorable kings and queens in Kings and Queens' Valley and tombs of workers in the Deir El Madina that have astonished the world with art, architecture, historical fragrant and various cultural heritage through various historical ages .

This great valuable heritage should be preserved through raising cultural awareness of individuals and correcting wrong patterns of social behavior that affect negatively these historical buildings. This civilization lasted for thousands of years and still exists, being inherited one generation after another. Awareness should be increased towards conserving this civilization in order to maintain and conserve it through
\end{abstract}

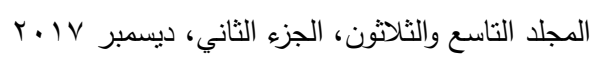


أحمد مصطفي العنيق وآخرون

maintenance, reparation, and restoration of buildings and monuments, protecting them also from robbery, destruction, and wreckage caused $y$ closeness of the inhabiting buildings and the agricultural lands which affect society economically, socially, culturally, and scientifically. There should be a habilitation of those historical buildings through shedding light on wrong social behaviors and diffusing cultural awareness. 